WIDER Working Paper 2018/58

Maternal mortality and women's political participation

Sonia Bhalotra, ${ }^{1}$ Damian Clarke, ${ }^{2}$ Joseph Gomes, ${ }^{3}$ and Atheendar Venkataramani ${ }^{4}$

May 2018 
Abstract: Raising women's political participation leads to faster maternal mortality decline. We estimate that the introduction of quotas for women in parliament results in a 9-12 per cent decline in maternal mortality. In terms of mechanisms, it also leads to an 8-11 per cent increase in skilled birth attendance and a 6-11 per cent increase in prenatal care utilization. We find reinforcing evidence from the period in which the United States experienced rapid declines in maternal mortality. The historical decline made feasible by the introduction of antibiotics was significantly greater in states that had longer exposure to women's suffrage.

Keywords: gender, maternal mortality, quotas, suffrage, women's political representation JEL classification: I14, I15, O15

\footnotetext{
${ }^{1}$ University of Essex, Colchester, United Kingdom; 2 Universidad de Santiago de Chile, Santiago, Chile; ${ }^{3}$ University of Navarra, Pamplona, Spain; ${ }^{4}$ University of Pennsylvania, Philadelphia, United States; corresponding author: srbhal@essex.ac.uk.

This research study is released in connection with the 17th Nordic Conference on Development Economics, jointly organized with Aalto University School of Business, University of Tampere, and the Nordic Network in Development Economics, on 11-12 June 2018 in Helsinki, Finland.
}

Copyright (C) UNU-WIDER 2018

Information and requests: publications@wider.unu.edu

ISSN 1798-7237 ISBN 978-92-9256-500-8 https://doi.org/10.35188/UNU-WIDER/2018/500-8

Typescript prepared by Gary Smith.

The United Nations University World Institute for Development Economics Research provides economic analysis and policy advice with the aim of promoting sustainable and equitable development. The Institute began operations in 1985 in Helsinki, Finland, as the first research and training centre of the United Nations University. Today it is a unique blend of think tank, research institute, and UN agency — providing a range of services from policy advice to governments as well as freely available original research.

The Institute is funded through income from an endowment fund with additional contributions to its work programme from Finland, Sweden, and the United Kingdom as well as earmarked contributions for specific projects from a variety of donors.

Katajanokanlaituri 6 B, 00160 Helsinki, Finland

The views expressed in this paper are those of the author(s), and do not necessarily reflect the views of the Institute or the United Nations University, nor the programme/project donors. 
Maternal mortality, defined as the death of women within 42 days of childbirth, remains a looming global health problem well into the twenty-first century. It is estimated to account for 830 deaths per day, and more than 216 deaths per 100,000 live births globally (Ceschia and Horton 2016). Maternal mortality is only the tip of the iceberg, the mass of which is maternal morbidity. In sub-Saharan Africa, the maternal mortality ratio (MMR) exceeds the rate in developed countries a century ago (Alkema et al. 2016; Loudon 1992). ${ }^{1}$ Although maternal mortality has declined rapidly in the last two decades, it was a late start, and there was massive variation in rates of decline. ${ }^{2}$ We leverage this variation to investigate the hypothesis that political will plays a significant role, and that women have greater political will for maternal mortality reduction. Since 1990, not only has the MMR fallen by 44 per cent, but the share of women in parliament has risen from under 10 per cent to more than 20 per cent (Figure 1a). We study whether these trends are causally related.

Persistence of high rates of maternal mortality is striking, given that the knowledge and technology needed to dramatically reduce it has been available for nearly a century, and the costs of intervention are relatively low (Cutler et al. 2006; Loudon 1992). That there remains far from universal coverage of reproductive health services suggests that addressing maternal mortality may be a low priority in some countries. Since 99 per cent of maternal mortality occurs in developing countries, a natural question is whether income has been a significant constraint to progress. While income has a positive association with each of female and male life expectancy, it exhibits only a weak relationship with the ratio of female to male life expectancy, a crude proxy for excess deaths of women associated with reproduction (see Figure A1). ${ }^{3}$ This suggests other factors at play, and we investigate gendered policy preferences. ${ }^{4}$

Since the share of women in parliament has been rising fairly smoothly, it can be hard to isolate its effects from those of other gradually evolving trends. We address this problem by exploiting the abrupt legislation of parliamentary gender quotas sweeping through developing countries since 1990. Figure $1 \mathrm{~b}$ shows that trends in women's share of seats in parliament track trends in quota coverage. We merge country-year quota implementation data with the first annualized estimates of MMR across countries, released in 2016, and estimate event study style regressions showing conditional trends in MMR pre- and post-quota adoption. We condition upon country and year fixed effects, income, and indicators for the quality of democracy. We scrutinize the assumption that quota implementation is quasi-random.

Our estimates show that passage of parliamentary gender quotas leads to an immediate 5-6 percentagepoint (55-66 per cent) increase in the share of parliamentary seats held by women, and a 9-12 per cent decrease in the MMR. These estimates are conditional on income and democracy, and not significantly modified by these controls. The effects of quotas are increasing in the share of seats reserved, and in time since implementation. There is no evidence of differential pre-trends, the estimates are robust to

\footnotetext{
${ }^{1}$ MMR is defined as deaths per 100,000 live births. In sub-Saharan Africa in 2015 it was 547; in the United States in 1936 it was 555 .

${ }^{2}$ In this period, MMR increased in a few countries, including the United States (MacDorman et al. 2016), which has the highest MMR among developed countries (Kassebaum et al. 2016). In 2015, MMR was 26.4 in the United States compared with 9.2 in the United Kingdom and 4.4 in Sweden per 100,000 live births. Research investigating the potential for women in politics to reverse this trend is merited.

${ }^{3}$ Duflo (2012) notes: 'other than pre-birth and in early childhood, women are most likely to be missing relative to men in childbearing years.' Deaths during the reproductive years account for 21 per cent of the six million women who go missing (i.e. comprise of the deficit in the difference between the actual and expected population sex ratio) each year (Wong 2012).

${ }^{4}$ Our estimates show that GDP growth is MMR-reducing, albeit less effective than implementation of gender quotas. Our purpose is to highlight that there remains considerable variation in MMR conditional upon income.
} 
controlling for potential predictors of quota implementation, including an index of women's rights, and bounds on the IV estimates (following Conley et al. (2012)) are negative.

Figure 1: Trends in gender quotas, women in parliament, and maternal mortality: (a) women in parliament and In(maternal mortality ratio); (b) reserved seats and women in parliament

(a)

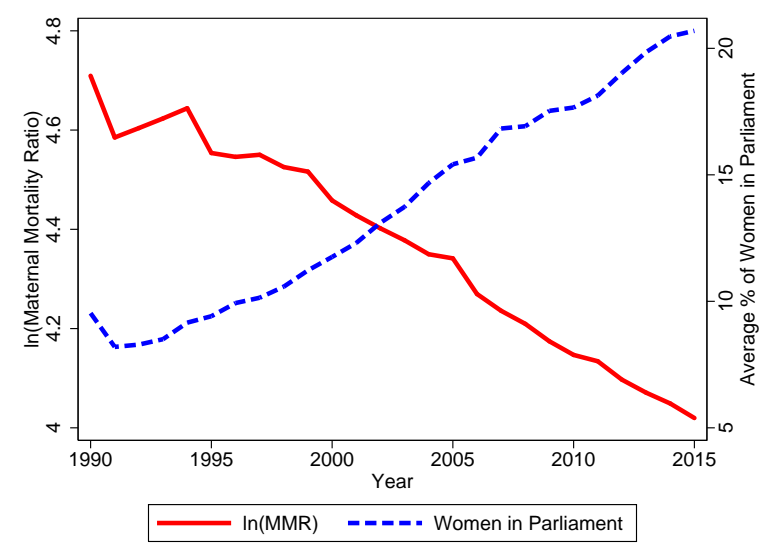

(b)

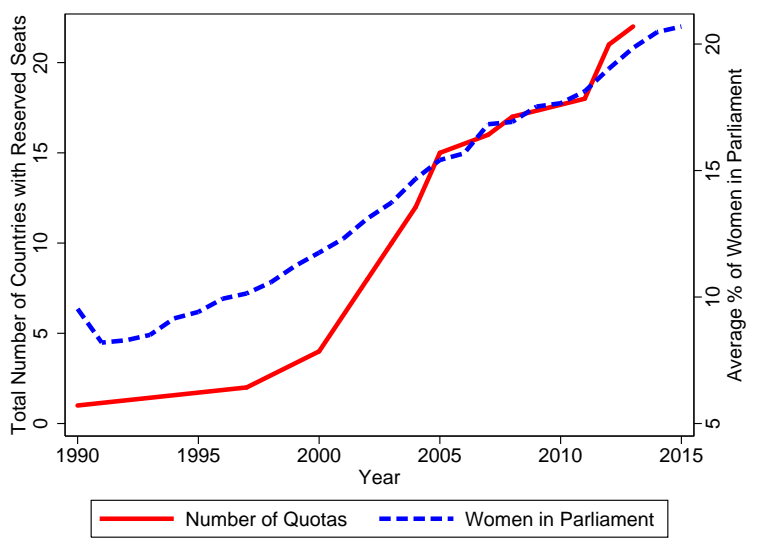

Notes: Raw trends in number of countries with parliamentary gender quotas, the percentage of women in parliamentary seats, and the log of the maternal mortality ratio. The sample is a global sample of 174 countries for which we have annual data for 1990-2015.

Source: data from the World Bank, World Development Indicators, Dahlerup (2005), the Global Database of Quotas for Women, and the Polity IV database. See Appendix 2 for further details.

Investment in key medical inputs appears to be an important mechanism. Gender quotas result in a 6.48.8 percentage-point (7.7-10.6 per cent) increase in skilled birth attendance and a 4.7-9.2 percentagepoint (5.7-11.1 per cent) increase in prenatal care utilization. The WHO recommends universal access to these inputs, and they are widely promoted as tools for maternal mortality reduction (Jamison et al. 2013; WHO 2014). ${ }^{5}$ We find no significant increase in health spending, suggesting the operative channel was reallocation of existing resources. Conditioning on health spending does not significantly alter the results. There is no significant impact of quotas on tuberculosis mortality (which affects both genders) or male mortality at reproductive ages. This indicates that women parliamentarians are effective in targeting women's health over and above any influence on overall health expenditures.

We further investigate the possibility that investments in medical inputs increase when women are involved in policy-making by studying the period when the United States experienced a sharp drop in

\footnotetext{
${ }^{5}$ In the only causal study available, Pettersson-Lidbom (2014) estimates that a 1 per cent increase in the share of midwifeassisted home births decreased MMR by 2 per cent in nineteenth-century Sweden.
} 
MMR following the introduction of antibiotics in 1937, which were effective in treating peripartum bacterial infections that accounted for a large share of maternal deaths (Jayachandran et al. 2010). In the early twentieth century, variation in women's influence on policy stemmed from suffrage (Kose et al. 2016; Miller 2008). We find that MMR fell more quickly in early-suffrage states after 1937: six years later, it was 15 per cent lower than the baseline difference. It seems plausible that states in which women have voted for longer are more sensitive to policies that favour women. We nevertheless also show that early-suffrage states had a 1.8 percentage-point larger share of women in the Senate in the post-antibiotic period, relative to a mean of 1.4 per cent.

Overall, using contemporary cross-country data across 25 years and historical cross-state data for the United States, both encompassing periods of dramatic decline in maternal mortality, we provide compelling new evidence that raising women's political participation can have substantial impacts on maternal mortality. Reserving 20-30 per cent of parliamentary seats for women results in an immediate decline of 17.7 per cent and, averaging across countries including those with smaller quotas, the decline in MMR ten years after implementation is 13 per cent. This compares favourably with the global decline in MMR of 44 per cent over the 25 years to $2015 .^{6}$ Efforts to reduce maternal mortality over this period focused on raising access to trained birth assistance, prenatal care, contraception, and women's education (Grépin and Klugman 2013; Kruk et al. 2016). There has been more limited recognition of the relevance of the political economy of resource allocation influencing these inputs. The 6-9 percentage-point increase in birth attendance and the 5-9 percentage-point increase in prenatal care that we demonstrate occurs in a year from quota passage compares well with the 12 percentage-point and 13 percentage-point increases achieved through the recent 25 years. Our findings show that giving political voice to women may be critical to effectively targeting maternal mortality.

Theoretical models of politician behaviour admit a role for politician identity (Besley and Coate 1997). A growing literature documents that women have different preferences from men (Niederle 2016) and, consistent with this, there is evidence that increasing the share of women politicians influences policy choices in favour of public goods or policies that align with the preferences of women (Chattopadhyay and Duflo 2004; Clots-Figueras 2012; Kose et al. 2016; Taylor-Robinson and Heath 2003; Swers 2005). Additionally, there is evidence that public health improves with women's political participation (Bhalotra and Clots-Figueras 2014; Miller 2008).

We make two contributions. First, we study impacts of the recent wave of implementation of gender quotas across countries; second, we are the first to propose that gender quotas can be an effective policy tool for maternal mortality reduction. This is important because the broader evidence on the success of quotas is mixed (Besley et al. 2017; Coate and Loury 1993; Niederle 2016; Pande and Ford 2012), and MMR has been difficult to bring down - for instance, the decline of 44 per cent since 1990 falls short of the Millennium Development Goal (MDG) target decline of 75 per cent (Hogan et al. 2010; Kassebaum et al. 2014). ${ }^{7}$

Previous work has documented the importance of population health for economic growth, via life expectancy and human capital accumulation. ${ }^{8}$ Reductions in maternal mortality have been argued to

\footnotetext{
${ }^{6}$ Our analysis period is the same, 1990-2015. However the estimated declines in this paper emerge from the 22 countries mandating quotas.

${ }^{7}$ Also, we use recent MMR data. Prior to release of these data in 2016, there were no annual time series for a comprehensive set of countries. This has no doubt contributed to maternal mortality being vastly understudied relative to, say, infant mortality.

${ }^{8}$ For example, Ashraf et al. (2009); Bloom et al. (2004); Soares (2005); Well (2007).
} 
favourably influence women's human capital attainment, employment, and growth (Albanesi and Olivetti 2014, 2016; Bloom et al. 2015; Jayachandran and Lleras-Muney 2009). ${ }^{9}$

\section{Gender quotas}

Since 1990, 22 countries have implemented constitutionally protected quotas reserving seats in parliament for women. Their geographic spread and trend are described in Figures A2 and A3. ${ }^{10}$ The impetus to adopt these policies was the unanimous signing of the Beijing Platform for Action by all UN delegates at the Fourth World Conference on Women in 1995, after which quota adoption accelerated (Chen 2010; Inter-Parliamentary Union 2015; Krook 2010). The Beijing Platform set a 30 per cent target for participation of women in decision-making in its 'agenda of women's empowerment' (UN Women 1995), but many countries mandated smaller shares - see Figure A4. Later we identify country-specific predictors of quota implementation. We merge quota data with MMR data and the estimation sample contains 174 countries, through 1990-2015. Summary statistics are in Table A1. Casual inspection suggests support for our hypothesis. Comparing country pairs with similar per capita gross domestic product (GDP) in 1990, selecting one which implemented quotas before 2010 and one which did not, we found that the quota-implementing country typically witnessed a larger decline in maternal mortality in 1990-2010. Thus, Rwanda did better than Malawi, Kenya did better than Zimbabwe, and Niger did better than the Democratic Republic of the Congo (DRC). ${ }^{11}$

\subsection{Empirical strategy}

To examine impacts of passage of gender quotas without restricting the timing of effects, we estimate an event study style regression:

$$
\begin{aligned}
Y_{c t}=\alpha+\sum_{l=2}^{10+} \beta_{l}^{\text {lead }} \text { Quota }_{c} & \times 1\left\{\text { lead }_{t}=l\right\}+\sum_{k=0}^{10+} \beta_{k}^{\text {lag }} \text { Quota }_{c} \times 1\left\{\text { lag }_{t}=k\right\} \\
& +X_{c t} \gamma+\mu_{t}+\varphi_{c}+\varepsilon_{c t} .
\end{aligned}
$$

The variation is across country $c$ and year $t$, the outcome $Y_{c t}$ is either the proportion of women in parliament or the maternal mortality ratio. Quota ${ }_{c}$ is 1 if a country ever adopted a quota, and this is interacted with a full set of leads and lags with respect to the year the quota was adopted. We include ten lags and leads; the tenth term includes all years greater than ten, and the first lead is omitted as the base category. The $\beta^{\text {lag }}$ coefficients capture the impacts of interest and the $\beta^{\text {lead }}$ coefficients test the identifying assumption of no differential pre-trends. We include country and year fixed effects $\left(\varphi_{c}\right.$ and $\mu_{t}$ respectively), and cluster standard errors at the country level (Bertrand et al. 2004).

We also present a parametric difference-in-difference (DD) specification in which the independent variable is defined as 1 for all years following the implementation of a quota for implementing countries, and

\footnotetext{
${ }^{9}$ Although see Bhalotra et al. (2018) for contrasting evidence showing increases in fertility and reductions in labour force participation.

${ }^{10}$ The countries in the sample are: Afghanistan, Algeria, Bangladesh, Burundi, China, Djibouti, Eritrea, Haiti, Iraq, Jordan, Kenya, Morocco, Niger, Pakistan, Rwanda, Saudi Arabia, South Sudan, Sudan, Swaziland, Tanzania, Uganda and Zimbabwe. Samoa implemented quotas in 2016 after the MMR data became available, and we do not have data for Kosovo, Somalia, and Taiwan, which have implemented quotas. Uganda is the only country that reserved seats before 1990, in 1989.

${ }^{11}$ Since 1990 the number of countries with candidate list quotas for women has also risen sharply, from 1 to 46 . We have no data for Palestine, but using the other 45 countries we found no impacts of list quotas on MMR. This may be because they have smaller impacts on women in parliament (we confirmed this), or because they were implemented mostly in Latin America, where MMR was already low and possibly harder to reduce.
} 
0 before. It is set to 0 for all countries that do not implement quotas in the sample period. As income and democracy are potentially correlated with both quotas and MMR, we include as time-varying covariates $X_{c t} \log$ GDP per capita, and a democracy score. In a specification check, we drop the 47 high-income countries from the sample so that the control group is more homogeneous. Although we provide a direct test of the parallel-trends assumption, we implement further checks showing bounds on IV estimates that allow for failure of the exclusion restriction (Conley et al. 2012), and test robustness to including potential predictors of quota legislation as controls in both estimating equations.

As the countries in the sample vary considerably in population size, we re-estimated the equation weighting by this. Solon et al. (2015) argue that this affords a test of model mis-specification. Since MMR varies considerably across countries, proportional changes implied by using logarithms will exaggerate achievements in countries with lower baseline rates (Deaton 2006). We therefore replaced the logarithm with the level of MMR. We also investigate intensive margin effects, exploiting variation in quota size, and we document how impacts evolve with duration.

We motivated the analysis by arguing that women policy makers are likely to be more effective in targeting women's health problems, but an alternative interpretation of our findings is that women cause generalized improvements in population health. To investigate this, we replace MMR with the log of male mortality for adults. This mirrors the age profile of MMR but isolates men. ${ }^{12}$ We also produce estimates for tuberculosis mortality.

\subsection{Results}

Estimates of Equation 1 are given in Figure 2. Figure 2a shows a discrete jump in women's parliamentary representation in the year after quotas are implemented. Figure $2 b$ also shows a break in the coefficient series, with maternal mortality falling more rapidly in quota-implementing countries. The drop is apparent in the year after implementation and becomes significant two years later. The lead coefficients allay concerns about endogeneity of policy adoption. Dropping high-income countries produces essentially identical estimates (Figure A5).

See Table A2 for the DD estimates. Following Figure 2, we allow a one-year lag for the share of women in parliament, and an additional year for impacts on maternal mortality. As the share of women can only change at the next election, we identified for every country the years between quota legislation and election. The mode and median are zero years, the mean is 1.3. Once women are in parliament, it seems plausible that it takes a year for any changes they induce to have discernible population-level impacts on maternal mortality. ${ }^{13}$ We find significant effects of gender quotas on the proportion of women in parliament of 5-6 percentage-points which, relative to the average in 1985-90 of 9 per cent, is 55-to 66 per cent. ${ }^{14}$ We also see a substantial reduction in MMR of 9-12 per cent.

\footnotetext{
${ }^{12}$ Mean MMR is 233 per 100,000 births, with range 3 to 2,890. The width of the range demonstrates the potential for reduction. Notice that mean male mortality in the reproductive age range is 238 per 1,000 male population, with range 58.8 to 689 (Table A1).

${ }^{13}$ The estimates are not sensitive to shrinking the lags since impacts endure.

${ }^{14}$ The median (mean) gender quota is 21 per cent (20 per cent). The estimated impacts are smaller. However, in quotaimplementing countries the pre-quota share of women in parliament was not always zero, the average was 7.9 per cent, rising to 20.9 per cent post-quota (median: 6.2 and 21.0 per cent). Taking all countries, the mean was 14.1 per cent, median 11.5 per cent (see Figures A6 and A7 for full distributions). See Figure A8 for temporal variation by country. In Rwanda we see a jump in line with quota legislation but from a high baseline, while Djibouti shows a sharp jump from zero to quota attainment. In some countries, it took time from quota passage until fulfilment. In Niger, for instance, the quota was in 2000 but the next election in 2004.
} 
Figure 2: Gender quotas: event studies for women in parliament and maternal mortality: (a) percentage of women in parliament; (b) In(maternal mortality ratio)

(a)

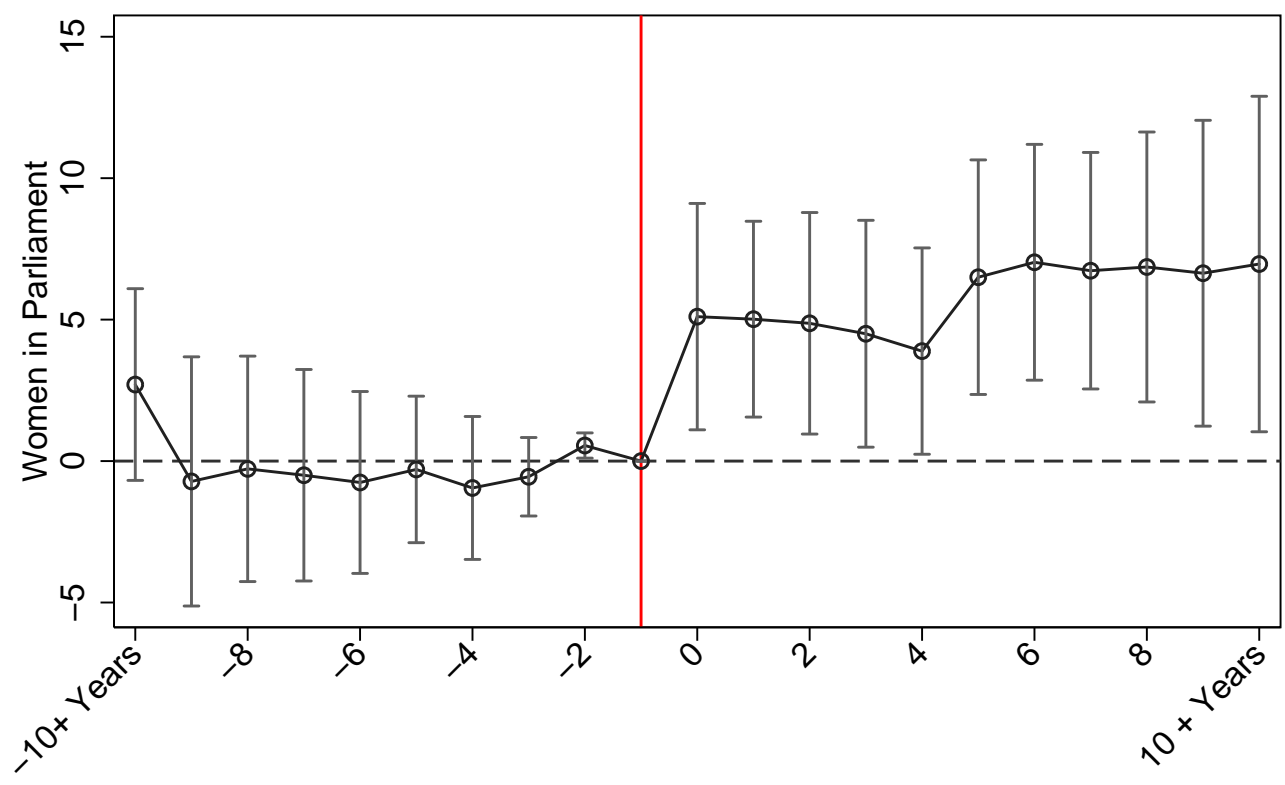

Time to Reform

○ Point Estimate $\longmapsto 95 \% \mathrm{Cl}$

(b)

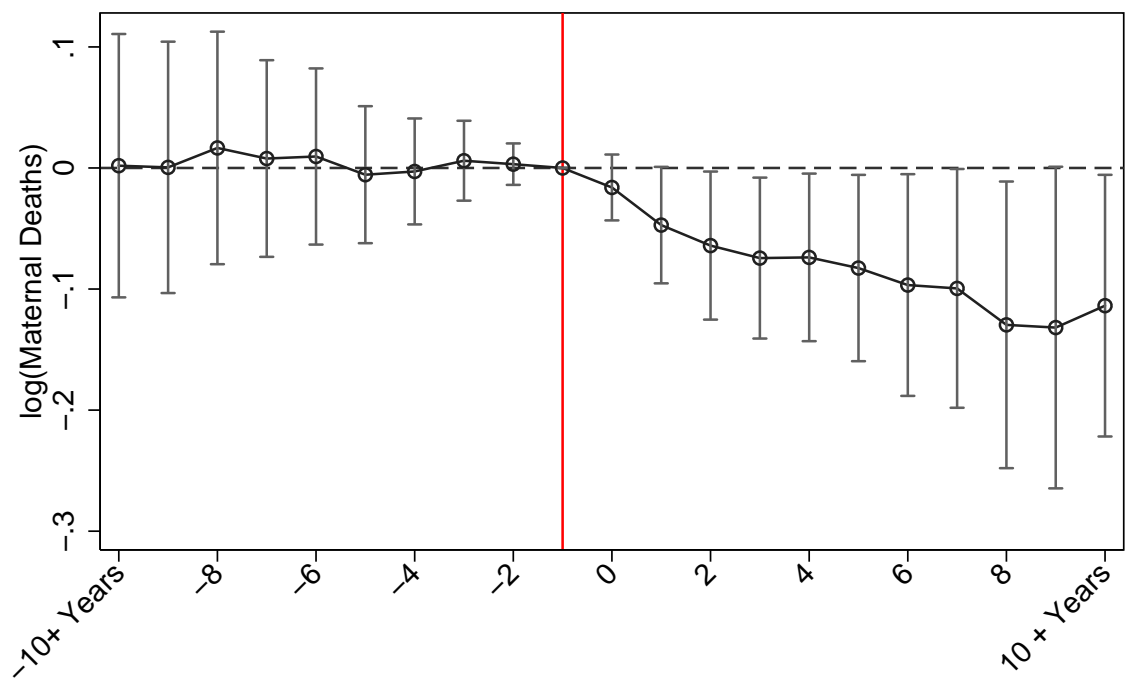

Time to Reform

o Point Estimate $\longmapsto 95 \% \mathrm{Cl}$

Notes: point estimates of the lag and lead terms in the event study specification described in equation 1 are presented, along with their 95 per cent confidence intervals. Estimates are conditional on country and year fixed effects, the natural logarithm of per capita GDP, and indicators for levels of the Polity IV democracy index. Time periods greater than ten years from the reform date are displayed as a single ' 10 +' indicator. Standard errors are clustered by country. The omitted base category is taken as one year prior to the reform, indicated by the solid vertical line.

Source: authors' calculations, based on data from the World Bank World Development Indicators, Dahlerup (2005), Global Database of Quotas for Women, and Polity IV Project Database. 
We have displayed estimates with and without population weights. Since China and India are outliers in population size, the weighted estimates exclude them. ${ }^{15}$ So as to isolate changes ensuing from weighting from changes associated with removing these countries, we also show unweighted estimates on the reduced sample. The point estimates are larger with China and India excluded, and again larger when weighted. However, all changes in the sequence are not statistically meaningful. Table A2 also shows that the estimates are robust to using level rather than log MMR. All estimates are conditional upon income and democracy. However, they are not sensitive to these controls; see Figure A9.

Democracy has direct impacts on both variables, increasing women in parliament and decreasing maternal mortality, but only when the score is above the mean. ${ }^{16}$ It is notable that income has no impact on the share of women in parliament, but it has a significant impact on MMR. A 1 per cent increase in GDP results in a 0.5 per cent reduction in MMR. A crude back-of-the-envelope calculation assuming log-linearity and holding democracy and quotas constant suggests that to achieve the estimated 9-12 per cent reduction in MMR due to quota adoption (on the same sample), GDP would have to increase by about $18-24$ per cent.

We observe increasing impacts over time as displayed in Figure 2b. By 10 years out, MMR was 13 per cent lower in countries that passed quotas. Intensive margin impacts of reserved seats are shown in Table A3. The estimates are rising in quota size, consistent with a 'dose-response' effect. The unweighted estimates indicate that quotas of less than 15 per cent have no significant impact, quotas of 15-20 per cent raise the share of women in parliament by 5.5 percentage-points and reduce MMR by 8.6 per cent, and the corresponding figures for quotas of 20-30 per cent are 7.7 percentage-points and 17.5 per cent respectively.

Although the event study plots largely allay potential concerns about omitted trends, we directly assess and address any bias in the regression coefficients associated with the possibility that when quotas were adopted, the country was already adopting other measures favourable to maternal mortality decline. To do this we estimate 2SLS regressions of MMR on the share of women in parliament, instrumented with quota implementation. Now the concern about omitted trends translates to a concern that the instrument is invalid; in particular, if quota implementation proxies a change in an omitted variable then it does not satisfy the IV exclusion restriction. However, as quota implementation is likely to be "plausibly exogenous' if not strictly so, we follow Conley et al. (2012) and provide bounds on the IV estimates. The first stage is in columns $1-3$ of Table A2. ${ }^{17}$ The second stage estimates are in Table A4. These provide the scaled impact of women's parliamentary representation among compliers. They indicate that a 1 percentage-point increase in women's share in parliament is associated with a 1.8 per cent decrease in MMR. In estimating bounds on the 2SLS estimates, we allow the adoption of quotas to have a direct impact on maternal mortality of up to -1 per cent over and above its impact on MMR via increasing women in parliament. The estimated bounds are informative, indicating a 0.1-3.2 per cent reduction in maternal mortality for a 1 percentage-point increase in the share of women in parliament (Table A4).

As the determinants of quota legislation are of substantive interest and previous work does not provide any clear quantitative analysis, we investigated them directly by acquiring country-year panel data on predictors that have been discussed in the political science literature, typically with reference to case

\footnotetext{
${ }^{15}$ China implemented quotas, India did not.

${ }^{16}$ Democracy raises women's share when the score is at least 6 on a $0-10$ scale, and directly impacts MMR when the score is 9 or 10.

${ }^{17}$ We note that the instrument does not always pass a weak instrument test, but present these as ancillary estimates.
} 
studies (Baines and Rubio-Marin 2005; Krook 2010); see Table A5. ${ }^{18}$ We include all of the potential predictors, including changes in women's rights, as controls in the estimated equations. If the predictors of quota legislation rather than the passage of the legislation drive impacts on MMR, then this would be revealed in the coefficient on quota legislation becoming insignificantly different from zero. Our estimates are, however, robust to these controls (Table A6).

The availability and quality of MMR data may be endogenous if surveillance and tracking are correlated with preferences in favour of addressing MMR decline. However, any bias this creates in the coefficient of interest will render our estimates conservative.

Finally, we find small or imprecisely estimated impacts of gender quotas on tuberculosis and male mortality (Table A7). As discussed, this suggests that the documented impacts on maternal mortality engage a mechanism over and above any positive impacts of women politicians on health expenditures, something we directly investigate in the next section.

\subsection{Mechanisms}

Having shown that increasing the share of women in parliament leads to more rapid declines in maternal mortality, we now seek to identify underlying mechanisms. As discussed earlier, we consider the health care interventions that the WHO recommends. Figure 3 shows an immediate rise in the share of women attending prenatal care and a lagged rise in the share of attended births. The DD estimates in Table A8 use a lag of two years on the quota variable (similar to the lag allowed for MMR), and demonstrate robustness to controls, to exclusion of India and China, and to population weights.

The passage of gender quotas is associated with a statistically significant $6.4-8.8$ percentage-point increase in skilled birth attendance and a 4.7-9.2 percentage point increase in the share of women using prenatal care. ${ }^{19}$ We find no significant impact of quotas on health spending. We nevertheless show in Figure A10 that the impact of quotas on maternal mortality is robust to including health expenditure as an additional control. ${ }^{20}$ In the next section, we investigate mechanisms further, using historical data for the United States. ${ }^{21}$

\footnotetext{
${ }^{18}$ The predictors include evolving norms of equality and representation and accelerating movements for women's rights, pressure from international organizations (which can be proxied with overseas development assistance), and occasions of broader constitutional reform, including transitions into democracy and post-conflict reconstruction (including peace-keeping forces). Using cross-country panel data methods, we find some evidence that transitions from autocratic rulers to democracy, recent changes in women's economic rights, and exposure to international organizations predict quota legislation.

${ }^{19}$ Crude regressions of MMR on these inputs using our analysis sample and conditioning on GDP and democracy show that a 1-percentage point increase in the share of attended births or women receiving prenatal care is associated with a 3.4 and 2.3 per cent decline in MMR respectively.

${ }^{20}$ As health expenditure is only available for a subset of the sample (years 1995-2013), introducing it as a control creates compositional effects. This is why it is not included in the main estimates.

${ }^{21}$ There may be other mechanisms at play - for instance, the increased visibility of women politicians may raise women's aspirations and education (Beaman et al. 2009), which may positively impact maternal health (Bhalotra and Clarke 2013).
} 
Figure 3: Mechanisms: event studies for impacts of gender quotas on intermediate outcomes: (a) antenatal care; (b) attended births

(a)

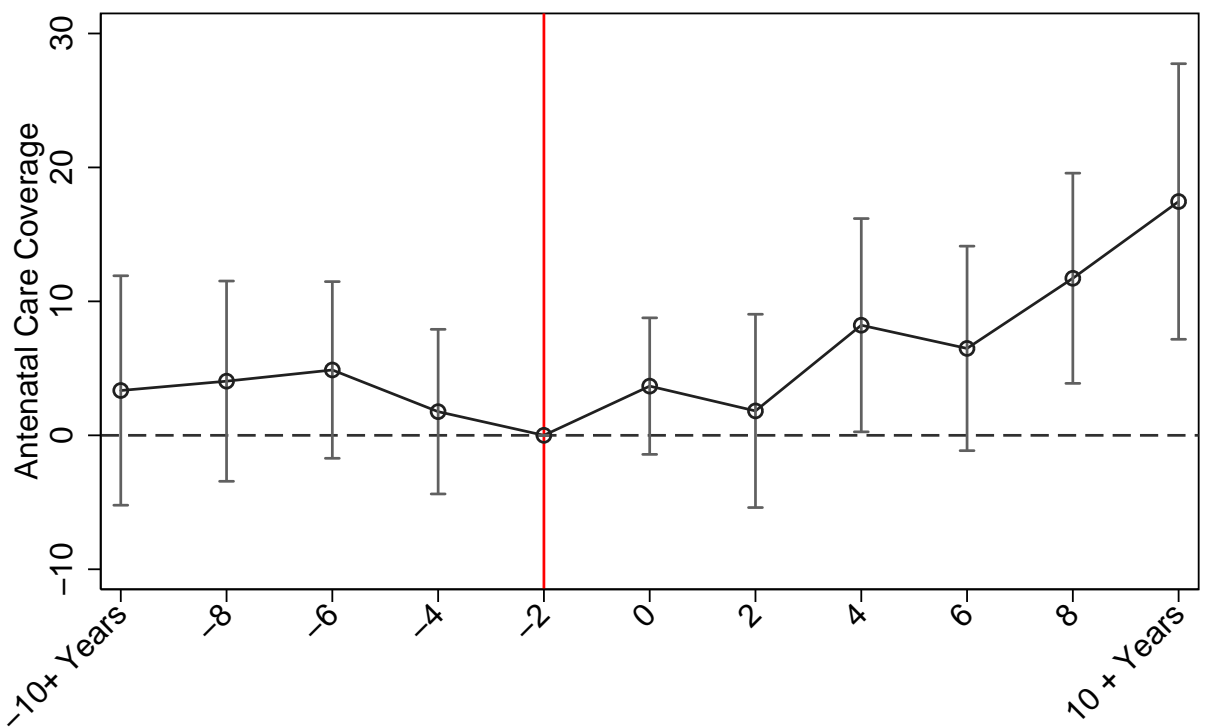

Time to Reform

$\circ$ Point Estimate $\longmapsto 95 \% \mathrm{Cl}$

(b)

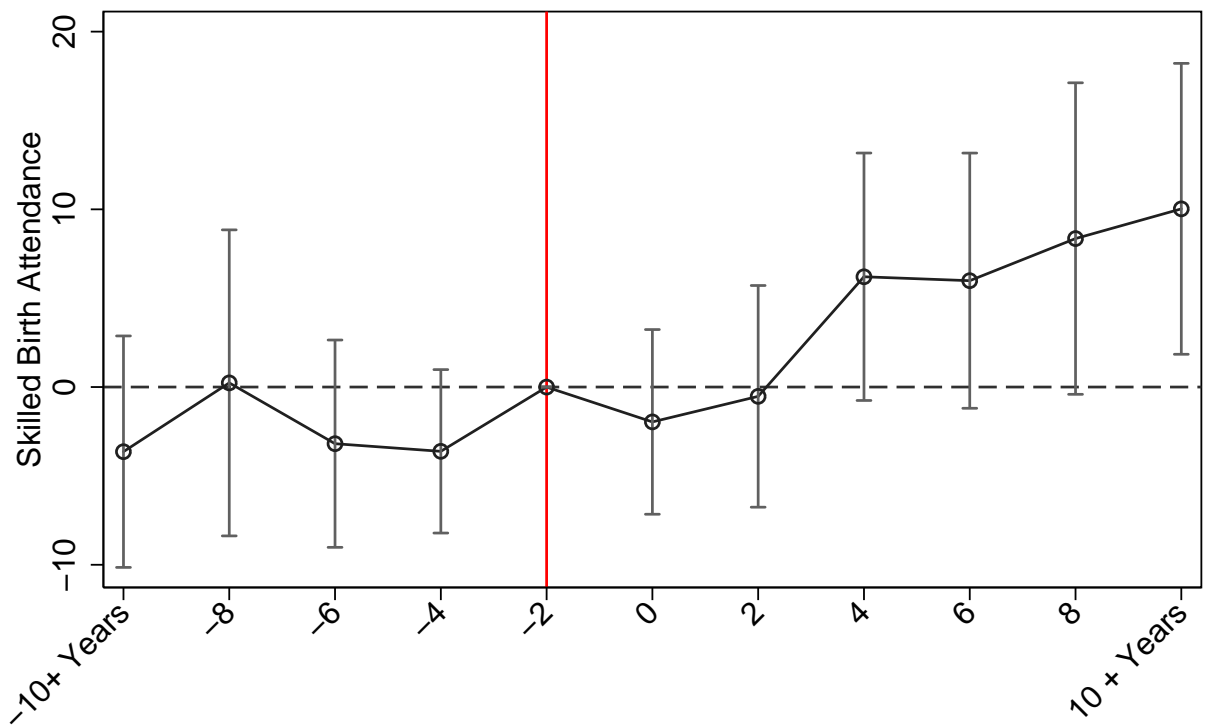

Time to Reform

○ Point Estimate $\longmapsto 95 \% \mathrm{Cl}$

Notes: Event-study estimates of intermediate outcomes as a function of the passage of gender quotas, following Equation 1. Antenatal coverage and birth attendance refer to the percentage of coverage, are accessed from the World Bank databank, and are only available for a sub-sample of years for each country (an unbalanced panel for the period 1990-2015). Given the unbalanced coverage of mechanism variables by countries and years, we present estimates pooling in two-yearly bins, rather than yearly bins, to avoid unbalanced coverage in particular lag and lead terms where possible. Event studies are conditional on country and year fixed effects only. We present DD models with a single post-quota indicator in Table A8, showing robustness to controls, and to weighting by population. Additional data descriptions are available in the Appendix.

Source: authors' calculations, based on data from the World Bank Databank, World Development Indicators database, Dahlerup (2005), and the Global Database of Quotas for Women. 
While changes in women's political participation in developing countries today are closely linked to gender quotas, in the era in which today's richer countries achieved steep declines in maternal mortality, much of the variation in women's voice in policy-making stemmed from dates of adoption of women's suffrage. To complement the preceding analysis, we identify the year in which maternal mortality in the United States showed a precipitous decline, and we analyse state variation in the size of this decline as a function of years since women's suffrage. To aid interpretation of our findings, we investigate whether early suffrage predicts the share of women in government in the period of rapid MMR decline.

\subsection{Background}

\section{Adoption of women's suffrage}

While the Nineteenth Amendment to the US Constitution, ratified in 1920, established women's suffrage nationwide, a number of states implemented women's suffrage prior to this mandate (Figure A11). Previous work has shown that state-level implementation of women's suffrage was associated with a sharp, 40 per cent rise in voter turnout in both the gubernatorial (Lott Jr. and Kenny 1999) and presidential elections (Kose et al. 2016), and an increase in the weight of women in policy-making (Miller 2008). We attempt to ratify one important channel for this by looking at whether early-suffrage states had more women in government in later years, after all states had implemented it. We collected data by state and year on the proportion of women in the House of Representatives (HoR) and the National Senate (Figure A12 and Table A9). In early adoption states relative to late adoption states (late being 1920), the share of women in the Senate is a statistically significant 1 percentage-point (110 per cent) higher in 1920-60 and 1.8 percentage-points (125 per cent) higher in 1937-43, the latter being the period of rapid maternal mortality decline within the analysis sample. The share of women in the HoR is 47 per cent higher in 1937-43, but this estimate is not precisely determined.

The drivers of differential timing of women's suffrage across states are reviewed by Miller (2008) and Kose et al. (2016). We summarize the relevant points here. States in the 'wild west' were the first to extend suffrage, all during the late nineteenth century. Some historians attribute this to harsh frontier conditions making it more difficult to sustain traditional gender roles (Brown 1958; Grimes 1967), but the quantitative literature has found no robust correlates of adoption dates (Cornwall et al. 2007). Importantly, there is no evidence that implementation of other gender-progressive policies that may have had direct impacts on maternal mortality decline was correlated with suffrage adoption. This includes regulation governing alimony and divorce, mother's pension, women's maximum work hours, women's minimum wages, prohibition, worker's compensation, child labour, compulsory schooling, and state attributes such as literacy rates and prevailing wages (Miller 2008). We will nevertheless investigate women's labour force participation as a control.

\section{Maternal mortality decline}

Sulfonamides, the first antibiotics, were effective in treating peripartum infections that accounted for about 40 per cent of maternal deaths (Albanesi and Olivetti 2016). Prior to their arrival, MMR in the United States was as high as it is in sub-Saharan Africa today, and penicillin did not arrive until 1942. There was an unprecedented and sharp drop in maternal mortality upon the introduction of sulfa in 1937. Importantly, the trend break in maternal mortality occurred at more or less the same time (in 1937 or 
1938) in all states (Jayachandran et al. 2010). However, we estimate that the post-1937 decline varied considerably across the states and investigate whether this was associated with variation in women's influence on policy-making. Browsing cases suggests it might have been. ${ }^{22}$

\subsection{Empirical strategy}

The hypothesis of interest is that, once a technology that could bring about large declines in maternal mortality became available, it was deployed more effectively in states that adopted women's suffrage earlier. The analysis sample is 1925-43, a short window around 1937, in which there were few largescale public health interventions. We estimate an event study style regression in which we interact an indicator for early suffrage adoption states with a set of leads and lags surrounding the arrival of sulfonamide drugs in 1937:

$$
\begin{aligned}
\ln (M M R)_{s t}= & \gamma_{0}+\sum_{j=2}^{12} \gamma_{j}^{\text {lead }} \operatorname{EarlySu}_{s} \times \mathbb{1}(\text { Year }=1937-j)_{t} \\
& +\sum_{k=0}^{6} \gamma_{k}^{\text {lag }} \text { EarlySuf }_{s} \times \mathbb{1}(\text { Year }=1937+j)_{t}+\varphi_{t}+\theta_{s}+v_{s t}
\end{aligned}
$$

where $s$ indexes states, $t$ indexes years, $\operatorname{EarlySu} f_{s}$ indicates states that legislated women's suffrage prior to the Nineteenth Amendment, and $\theta_{s}$ and $\varphi_{t}$ represent state and year fixed effects. Standard errors are clustered at the state level. We also show the corresponding DD style regression in which we interact an indicator for early-adoption states with an indicator for the post-antibiotic years, allowing for trend as well as level differences by including a further interaction with year. As tracking maternal mortality is potentially a political choice, we re-estimate the model restricting the sample to a balanced panel so as to account for any correlation between data on maternal mortality and women's suffrage. We also investigate sensitivity of the results to weighting the regressions with state population.

We interpret early suffrage as a proxy for the strength of women's voice in policy-making as it is plausible that this increases with years of exposure to women being able to vote, and we show that in addition it is associated with more women being in government, which gives them more of a direct handle on policy-making. An alternative interpretation may be that early adopters of suffrage had an underlying tendency to be gender progressive, and that they would have had faster declines in MMR irrespective of any influence of women in policy-making. First, we cited results from Miller (2008) that undermine this concern. Second, we nevertheless control for women's labour force participation, interacting it with the post-antibiotic dummy. Third, it would show as a differentially steeper pre-trend in MMR in earlyversus late-suffrage states, a test of which is provided by the significance of the $\gamma^{\text {lead }}$ terms.

As discussed for the quota case, an interpretation of our findings is that women's political participation was associated with better public health provision in general, but not necessarily focused on women. This would still be interesting, but our thesis is more specific. So as to be able to make this differentiation, we estimated an equation similar to equation 2 for infant pneumonia mortality as this was (1) treatable with sulfa drugs (Jayachandran et al. 2010), and (2) affected both genders. Among children (the age group with the highest infection rates) it affected boys more than girls (Bhalotra and Venkataramani 2014).

\footnotetext{
${ }^{22}$ For instance, Colorado extended the franchise to women in 1893, 27 years before neighbouring New Mexico or Alabama did in 1920. In 1936, MMR in Colorado, New Mexico, and Alabama was similar, at 710, 740, and 740 respectively. By 1950, MMR in Colorado had fallen to 80, just below the US average of 86, while in New Mexico and Alabama it was still about double the US average at 150 and 170 respectively (national-level summary statistics are in Table A10). In contemporary America, Colorado ranks 4th in women's political representation, while Alabama ranks 46th, and these differences are persistent. While New Mexico ranks 14th now, it ranked 34th in 1975. See www.cawp.rutgers.edu/state_fact_sheets.
} 


\subsection{Results}

The event study plot is in Figure 4a. Maternal mortality fell sharply in 1937 and five years later the average decline was 50 per cent, with state-specific declines varying between 6 and 80 per cent. We show that some of this variation is explained by duration of exposure to women's suffrage. We find that MMR declined more rapidly in states that adopted suffrage early. The early adopters had lower levels of MMR in the pre-antibiotic era and, after 1937, the gap between early and late adopters widened. Before 1937, MMR in early-adopting states was lower than in late-adoption states by 11 per cent. Six years later, this gap had widened to 26 per cent, resulting in an estimated impact of a 15 per cent reduction. However, there was no statistically significant difference in the trend in MMR in the pre-antibiotic era between the two groups of states - that is, no differential pre-trends. Our findings are robust to including interactions of baseline women's labour force participation with the post-sulfa dummy, year, and the interaction of post and year. They are also robust to restricting the sample to a balanced panel to account for endogenous tracking of maternal mortality, and to weighting by state population (see Figure A13).

The DD style regression is in Table A11. We see a similar pattern of results with and without state population weights, but the estimates are larger and more precise with weights. They indicate that the level drop in MMR was 8.5 per cent larger in early-adopting states (coefficient on early adoption $\times$ post-antibiotic), and that the trend decline was 1.5 per cent faster (coefficient on early adoption $\times$ postantibiotic $\times$ year). The event study for pneumonia mortality (Figure 4b) shows that although there were large declines in pneumonia following the introduction of antibiotics (Bhalotra and Venkataramani 2014; Jayachandran et al. 2010), there was no significant difference in the post-sulfa rates of decline in earlyversus late-suffrage adopting states.

\section{Conclusion}

Our findings suggest that neither increases in country income nor advances in medical technology are sufficient for the realization of potential improvements in maternal mortality. The new evidence we provide, documenting that women's involvement in policy-making can effect more rapid maternal mortality decline has implications for the recently launched Global Health 2035 report, and the ambitious Sustainable Development Goals. The MDG target was not met and the SDG target is more ambitious, so we clearly need some policy innovation. In fact this paper shows that SDG 3.1 for reducing maternal mortality is complementary to SDG 5.5 for raising the share of women in parliament. Given recent evidence from analysis of close elections in India which shows that replacing men legislators with women legislators would incur no cost in terms of compromised economic growth (Baskaran et al. 2015), gender quotas may be both a powerful and low-cost means to modifying public health priorities and improving maternal health. Despite significant progress, especially since 2000, preventable maternal mortality remains high. The lifetime risk of maternal mortality is 1 in 41 women in low-income countries. Despite a wave of gender quota implementation, 130 countries in the world have none. There is thus substantial room for manoeuvre. 
Figure 4: Women's suffrage: event studies for maternal mortality and pneumonia mortality: (a) In(maternal mortality ratio; (b) In(rate of infant pneumonia mortality)

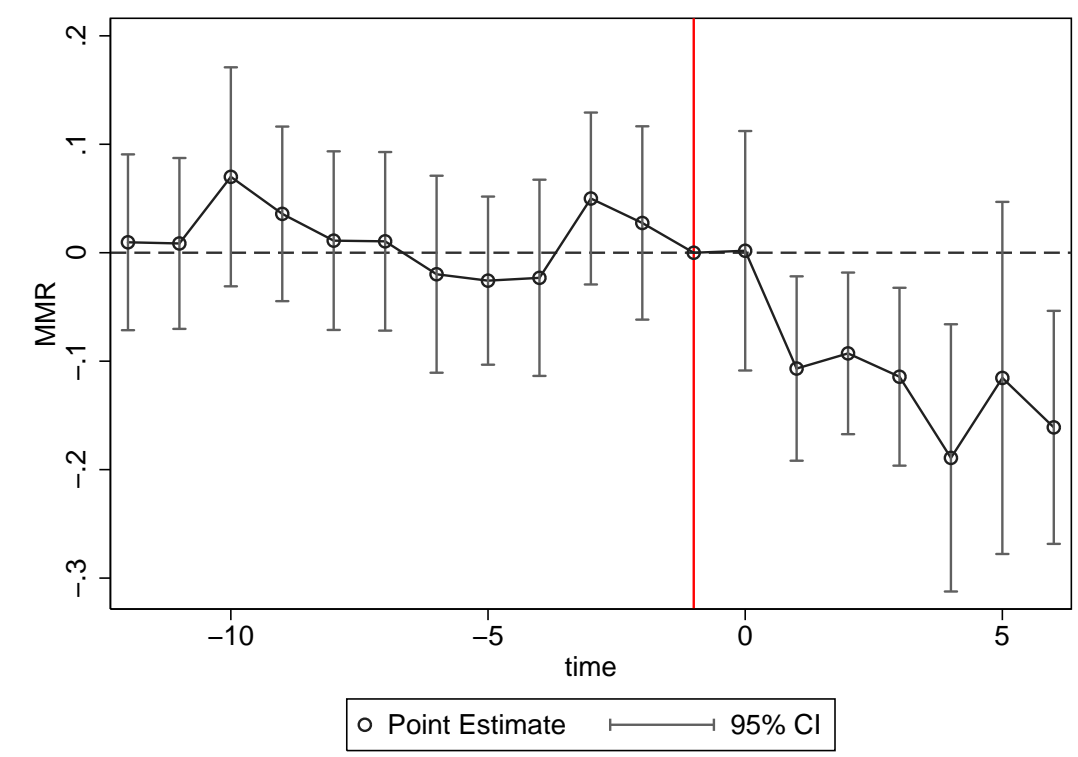

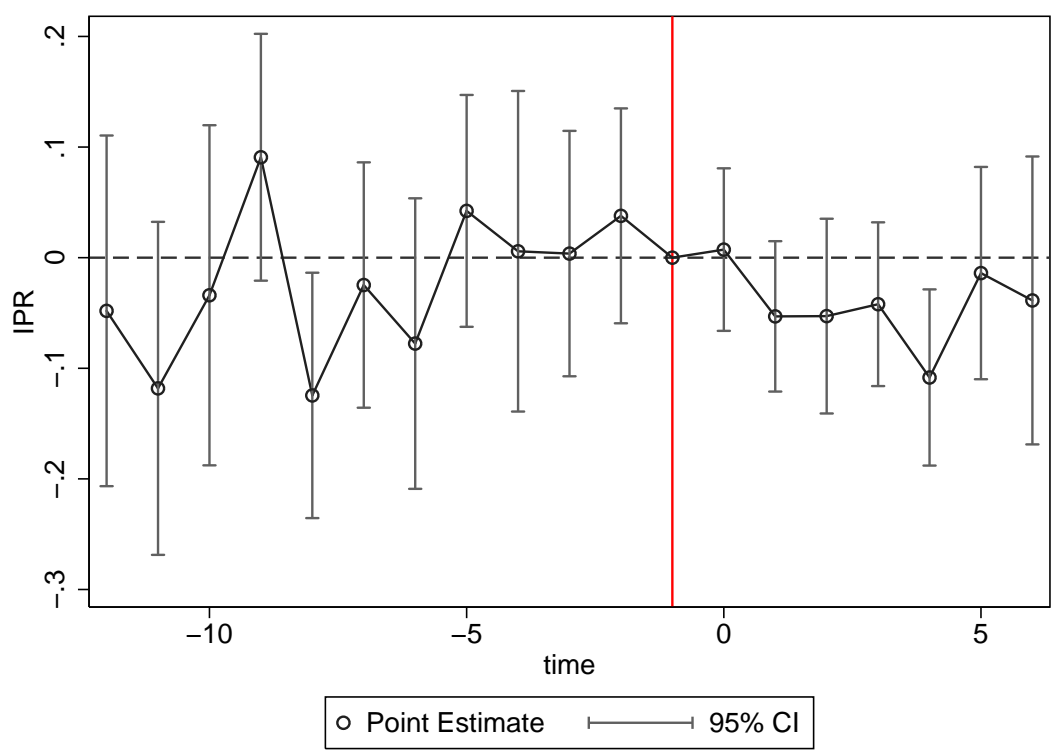

Notes: Event study plots differential rates of reduction of maternal mortality ratios (panel A) and infant pneumonia mortality rates (panel B) in early relative to late suffrage states, surrounding the arrival of Sulfa drugs (year 0 ). The omitted year is -1 . All estimates are with respect to the prevailing differential one year prior to the reform. Standard errors associated with the $95 \%$ confidence intervals are clustered by state.

Source: authors' calculations, based on data from US Vital Statistics (via Jayachandran et al. 2010) and Miller (2008). See Appendix 2 for further details. 


\section{References}

Albanesi, S., and C. Olivetti. (2014). 'Maternal Health and the Baby Boom'. Quantitative Economics, 5(2): 225-69.

Albanesi, S., and C. Olivetti. (2016). 'Gender Roles and Medical Progress'. Journal of Political Economy, 124(3): 650-95.

Alkema, L., D. Chou, D. Hogan, S. Zhang, A.-B. Moller, A. Gemmill, D. Ma Fat, T. Boerma, M. Temmerman, C. Mathers, and L. Say. (2016). 'Global, Regional, and National Levels and Trends in Maternal Mortality Between 1990 and 2015, with Scenario-Based Projections to 2030: a Systematic Analysis by the UN Maternal Mortality Estimation Inter-Agency Group'. The Lancet, 387(10017): 462-74.

Alkema, L., S. Zhang, D. Chou, A. Gemmill, A.-B. Moller, D. Ma Fat, L. Say, C. Mathers, and D. Hogan. (2017). 'A Bayesian Approach to the Global Estimation of Maternal Mortality'. The Annals of Applied Statistics, 11(5): 1245-74.

Ashraf, Q.H., A. Lester, and D.N. Weil. (2009). 'When Does Improving Health Raise GDP?' Working Paper 14449. Cambridge, MA: National Bureau of Economic Research.

Baines, B., and R. Rubio-Marin. (2005). The Gender of Constitutional Jurisprudence. Cambridge: Cambridge University Press.

Baskaran, T., S. Bhalotra, B. Min, and Y. Uppal. (2015). 'Female Legislators and Economic Growth: Evidence from State Elections in India'. Goettingen: University of Goettingen. https://editorialexpress.com/cgi-bin/conference/download.cgi?db_name= NEUDC2015\&paper_id=391.

Beaman, L., R. Chattopadhyay, E. Duflo, R. Pande, and P. Topalova. (2009). 'Powerful Women: Does Exposure Reduce Bias?'. Quarterly Journal of Economics, 124(4): 1497-540.

Beck, T., G. Clarke, A. Groff, P. Keefer, and P. Walsh. (2001). 'New Tools in Comparative Political Economy: The Database of Political Institutions'. World Bank Economic Review, 15(1): 165-76.

Bertrand, M., E. Duflo, and S. Mullainathan. (2004). 'How Much Should We Trust Differences-InDifferences Estimates?'. Quarterly Journal of Economics, 119(1): 249-75.

Besley, T., and S. Coate. (1997). 'An Economic Model of Representative Democracy'. Quarterly Journal of Economics, 112(1): 85-114.

Besley, T., O. Folke, T. Persson, and J. Rickne. (2017). 'Gender Quotas and the Crisis of the Mediocre Man: Theory and Evidence from Sweden'. American Economic Review, 107(8): 2204-42.

Bhalotra, S., and A. Venkataramani. (2014). 'Shadows of the Captain of the Men of Death: Early Life Health Interventions, Human Capital Investments, and Institutions'. Colchester: University of Essex.

Bhalotra, S., and D. Clarke. (2013). 'Educational Attainment and Maternal Mortality'. UNESCO Background Paper 2013/42014/ED/EFA/MRT/PI/14. Paris: UNESCO

Bhalotra, S., and I. Clots-Figueras. (2014). 'Health and the Political Agency of Women'. American Economic Journal: Economic Policy, 6(2): 164-97.

Bhalotra, S., A. Venkataramani, and S. Walther. (2018). 'Fertility Responses to Reductions in Mortality: Quasi-Experimental Evidence from 20th Century America'. Mimeo. 
Bloom, D.E., D. Canning, and J. Sevilla. (2004). 'The Effect of Health on Economic Growth: A Production Function Approach'. World Development, 32(1): 1-13.

Bloom, D.E., M. Kuhn, and K. Prettner. (2015). 'The Contribution of Female Health to Economic Development'. Working Paper 21411. Cambridge, MA: National Bureau of Economic Research.

Brown, D. (1958). The Gentle Tamers: Women of the Old Wild West. Lincoln, NE: University of Nebraska Press.

Ceschia, A., and R. Horton. (2016). 'Maternal Health: Time for a Radical Reappraisal'. The Lancet, 388(10056): 2064-66.

Chattopadhyay, R., and E. Duflo. (2004). 'Women as Policy Makers: Evidence from a Randomized Policy Experiment in India'. Econometrica, 72(5): 1409-43.

Chen, L.-J. (2010). 'Do Gender Quotas Influence Women's Representation and Policies?' European Journal of Comparative Economics, 7(1): 13-60.

Cingranelli, D.L., D.L. Richards, and K.C. Clay (2013). 'The CIRI human rights dataset'. Version 2013.12.05. www. humanrightsdata.org.

Clots-Figueras, I. (2012). 'Are Female Leaders Good for Education? Evidence from India'. American Economic Journal: Applied Economics, 4(1): 212-44.

Coate, S., and G.C. Loury. (1993). 'Will Affirmative-Action Policies Eliminate Negative Stereotypes?' The American Economic Review, 83: 1220-40.

Conley, T.G., C.B. Hansen, and P.E. Rossi. (2012). 'Plausibly Exogenous'. Review of Economics and Statistics, 94(1): 260-72.

Cornwall, M., B. King, E. Legerski, E. Dahlin, and K. Schiffman. (2007). 'Signals or Mixed Signals: Why Opportunities for Mobilization are not Opportunities for Policy Reform'. Mobilization: An International Quarterly, 12(3): 239-54.

Cutler, D., A. Deaton, and A. Lleras-Muney. (2006). 'The Determinants of Mortality'. Journal of Economic Perspectives, 20(3): 97-120.

Dahlerup, D. (2005). 'Increasing Women's Political Representation: New Trends in Gender Quotas'. In J. Ballington and A. Karam (eds), Women in Parliament: Beyond Numbers. Stockholm: International Institute for Democracy and Electoral Assistance.

Deaton, A. (2006). 'Global Patterns of Income and Health: Facts, Interpretations, and Policies'. Working Paper 12735. Cambridge, MA: National Bureau of Economic Research.

Duflo, E. (2012). 'Women Empowerment and Economic Development'. Journal of Economic Literature, 50(4): 1051-79.

Grépin, K. A, and Jeni Klugman. (2013). 'Maternal Health: A Missed Opportunity for Development'. The Lancet, 381(9879): 1691-93.

Grimes, A.P. (1967). The Puritan Ethic and Woman Suffrage. New York: Oxford University Press.

Hogan, M.C., K.J. Foreman, M. Naghavi, S.Y. Ahn, M. Wang, S.M. Makela, A.D. Lopez, R. Lozano, and C.J.L. Murray. (2010). 'Maternal Mortality for 181 Countries, 1980-2008: A Systematic Analysis of Progress Towards Millennium Development Goal 5'. The Lancet, 375(9726): 1609-23.

Inter-Parliamentary Union. (2015). Women in Parliament: 20 Years in Review. Geneva: IPU. 
Jamison, D.T., L.H. Summers, G. Alleyne, K.J. Arrow, S. Berkley, A. Binagwaho, F. Bustreo, D. Evans, R.G.A. Feachem, J. Frenk, G. Ghosh, S.J. Goldie, Y. Guo, S. Gupta, R. Horton, M.E. Kruk, A. Mahmoud, L.K. Mohohlo, M. Ncube, A. Pablos-Mendez, K.S. Reddy, H. Saxenian, A. Soucat, K.H. Ulltveit-Moe, and G. Yamey. (2013). 'Global Health 2035: A World Converging Within a Generation'. The Lancet, 382(9908): 1898-955.

Jayachandran, S., A. Lleras-Muney, and K.V. Smith. (2010). 'Modern Medicine and the Twentieth Century Decline in Mortality: Evidence on the Impact of Sulfa Drugs'. American Economic Journal: Applied Economics, 2(2): 118-46.

Jayachandran, S., and A. Lleras-Muney. (2009). 'Life Expectancy and Human Capital Investments: Evidence from Maternal Mortality Declines'. The Quarterly Journal of Economics, 124(1): 349-97.

Kassebaum, N.J., A. Bertozzi-Villa, M.S. Coggeshall, K.A. Shackelford, C. Steiner, K.R. Heuton, D. Gonzalez-Medina, R. Barber, C. Huynh, D. Dicker, et al. (2014). 'Global, Regional, and National Levels and Causes of Maternal Mortality During 1990-2013: A Systematic Analysis for the Global Burden of Disease Study 2013'. The Lancet, 384: 980-1004

Kassebaum, N.J., R.M. Barber, Z.A. Bhutta, L. Dandona, P.W. Gething, S.I. Hay, Y. Kinfu, H.J. Larson, X. Liang, S.S Lim, et al. (2016). 'Global, Regional, and National Levels of Maternal Mortality, 19902015: A Systematic Analysis for the Global Burden of Disease Study 2015'. The Lancet, 388(10053): 1775-812.

Kose, E., E. Kuka, and N. Shenhav. (2016). 'Women's Enfranchisement and Children's Education: The Long-Run Impact of the U.S. Suffrage Movement'. Discussion Paper 10148. Bonn: Institute for the Study of Labor (IZA).

Krook, M.L. (2010). Quotas for Women in Politics: Gender and Candidate Selection Reform Worldwide. Oxford: Oxford University Press.

Kruk, M.E., S. Kujawski, C.A. Moyer, R.M. Adanu, K. Afsana, J. Cohen, A. Glassman, A. Labrique, K S. Reddy, and G. Yamey. (2016). 'Next Generation Maternal Health: External Shocks and HealthSystem Innovations'. The Lancet, 388(10057): 2296-306.

Lott Jr., J.R, and L.W. Kenny. (1999). 'Did Women's Suffrage Change the Size and Scope of Government?' Journal of Political Economy, 107(6): 1163-98.

Loudon, I. (1992). Death in Childbirth: An International Study of Maternal Care and Maternal Mortality 1800-1950. Oxford: Clarendon Press.

MacDorman, M.F., E. Declercq, H. Cabral, and C. Morton. (2016). 'Is the United States Maternal Mortality Rate Increasing? Disentangling Trends from Measurement Issues'. Obstetrics \& Gynecology, 128(3): 447.

Manning, J.E., and Ida A. Brudnick. (2018). 'Women in Congress, 1917-2018: Service Dates and Committee Assignments by Member, and Lists by State and Congress'. Congressional Research Service CRS Report.

Miller, G. (2008). 'Women's Suffrage, Political Responsiveness, and Child Survival in American History'. Quarterly Journal of Economics, 123(3): 1287-327.

Niederle, M. (2016). 'Gender'. In J.H. Kagel and A.E. Roth (eds), The Handbook of Experimental Economics, Volume 2, 2nd edition. Princeton: Princeton University Press.

Pande, R., and D. Ford. (2012). Gender Quotas and Female Leadership. Washington, DC: World Bank. 
Paxton, P., J. Green, and M. Hughes. (2008). 'Women in Parliament, 1945-2003: Cross-National Dataset'. ICPSR24340-v1. Ann Arbor, MI: Inter-university Consortium for Political and Social Research (distributor).

Pettersson-Lidbom, P. (2014). 'Midwives and Maternal Mortality: Evidence from a Midwifery Policy Experiment in Sweden in the 19th century'. Mimeo.

Soares, R.R. (2005). 'Mortality Reductions, Educational Attainment, and Fertility Choice'. American Economic Review, 95(3): 580-601.

Solon, G., S.J. Haider, and J.M. Wooldridge. (2015). 'What Are We Weighting For?'. Journal of Human Resources, 50(2): 301-16.

Swers, M.L. (2005). 'Connecting Descriptive and Substantive Representation: An Analysis of Sex Differences in Cosponsorship Activity'. Legislative Studies Quarterly, 30(3): 407-33.

Taylor-Robinson, M.M., and R.M. Heath. (2003). 'Do Women Legislators have Different Policy Priorities Than Their Male Colleagues? A Critical Case Test'. Women \& Politics, 24(4): 77-101.

UN Women. (1995). 'Beijing Declaration and Platform for Action'. www.un.org.womenwatch/daw/ beijing/pdf/BDPfA20E.pdf (accessed 22 February 2017).

Well, D.N. (2007). 'Accounting for the Effect of Health on Economic Growth'. Quarterly Journal of Economics, 122(3): 1265-306.

WHO. (2014). 'Maternal Mortality, Fact Sheet Number 348'. Geneva: WHO.

Wong, Y.N. (2012). 'World Development Report 2012: Gender Equality and Development'. Forum for Development Studies, 39: 435-44. 


\section{Appendix 1}

Figure A1: Life expectancy in 2010: (a) female life expectancy; (b) male life expectancy; (c) female/male life expectancy ratio

(a)

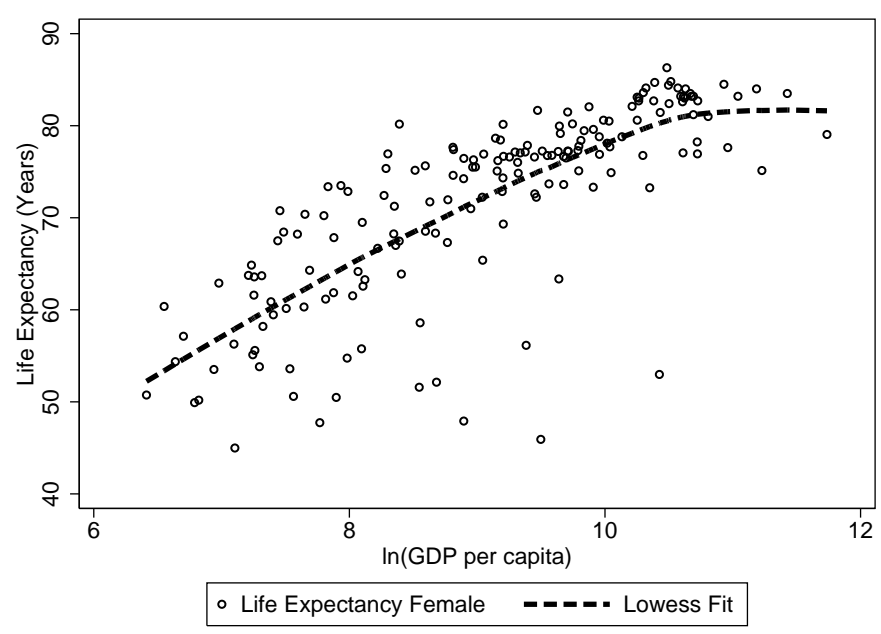

(b)

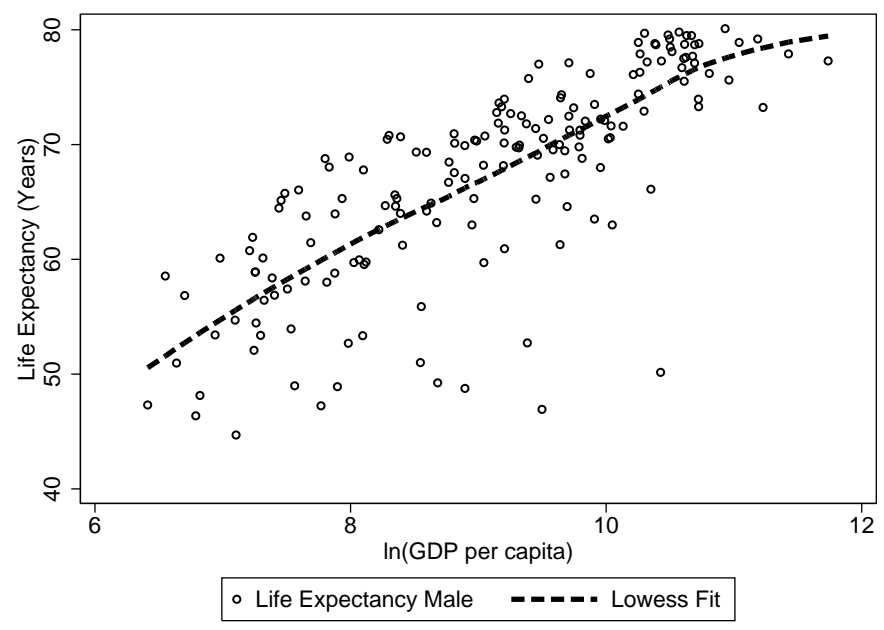

(c)

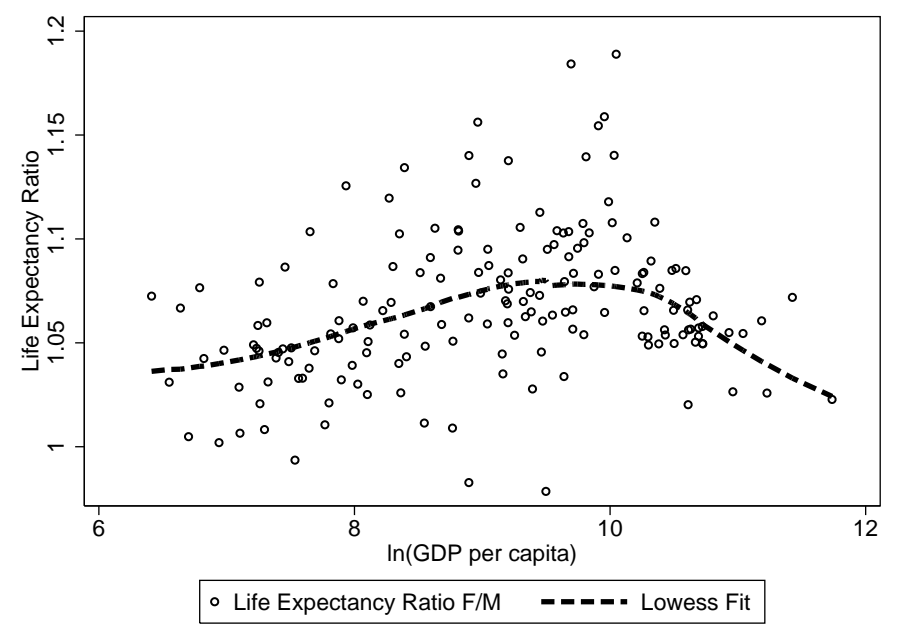

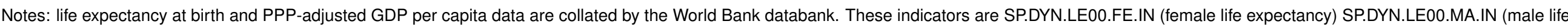

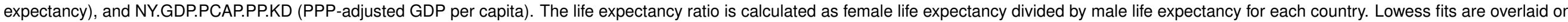
scatter plots, using a bandwidth of 0.8 for local linear smoothing.

Source: authors, based on data from the World Bank World Development Indicators. 
Figure A2: Reserved seat quota coverage: 1990-2015

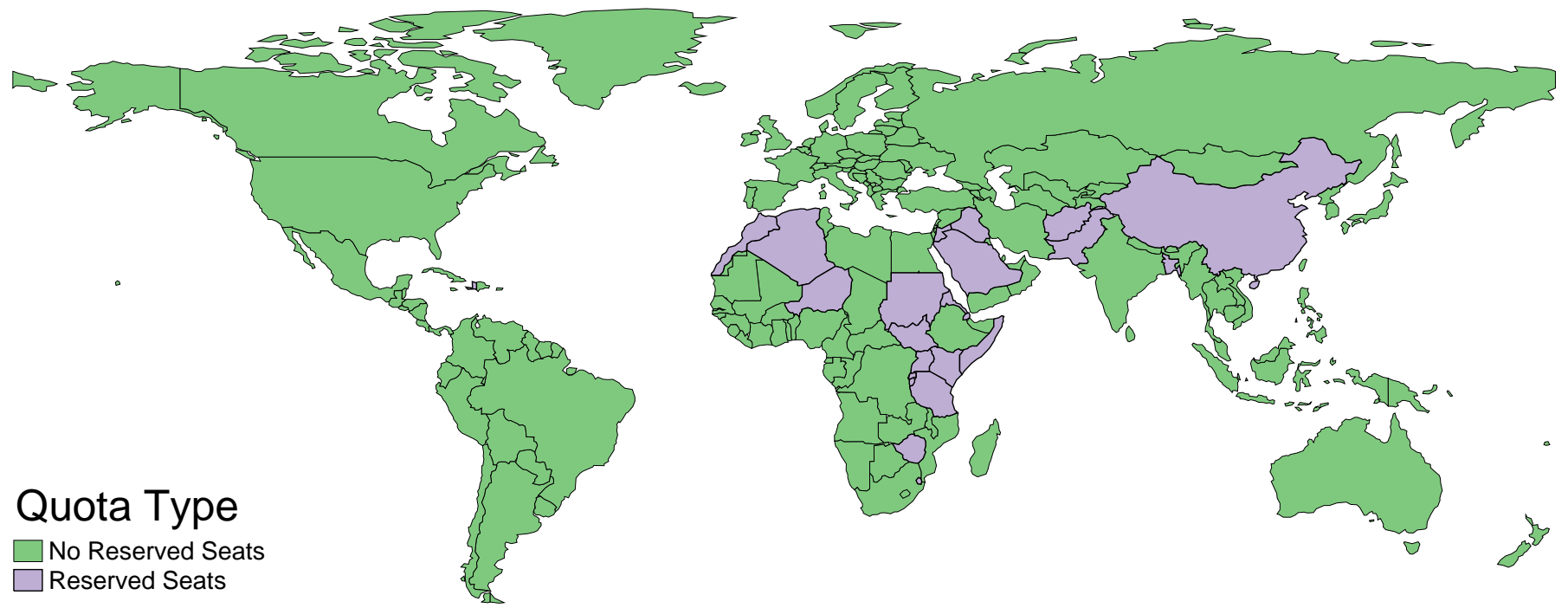

Notes: geographic distribution of countries implementing a quota for reserved seats in parliament.

Source: data compiled from Dahlerup (2005) and updated with information for recent years from the online quotaproject.org database developed and maintained by the International Institute for Democracy and Electoral Assistance (IDEA), the Inter-Parliamentary Union, and Stockholm University. This database was consulted on 19 July, 2016

Figure A3: Reserved seat quota timing: 1990-2012

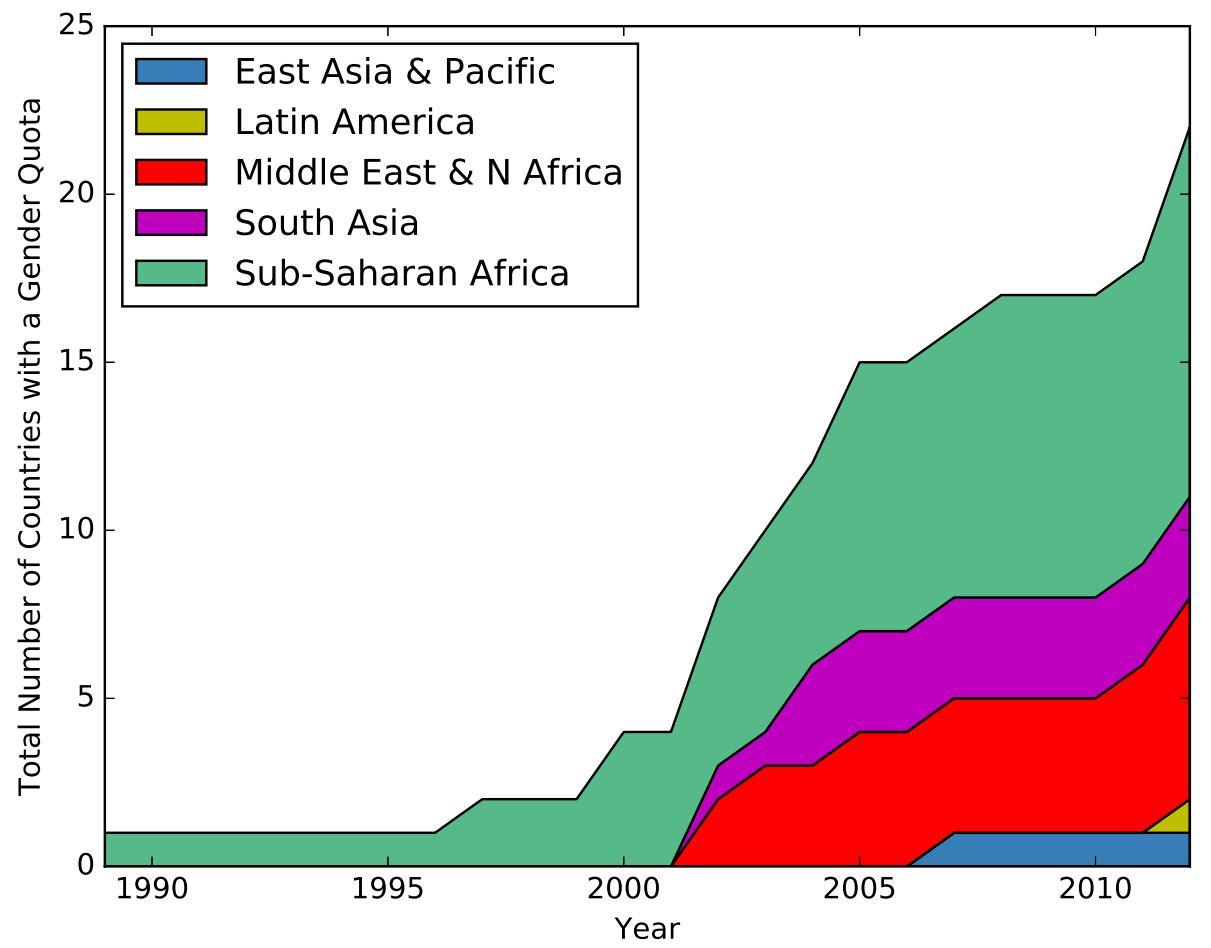

Notes: timing of the implementation of reserved seats by geographic area.

Source: authors' calculations based on data from Dahlerup (2005) and Global Database of Quotas for Women. 
Figure A4: Reserved seat quota sizes

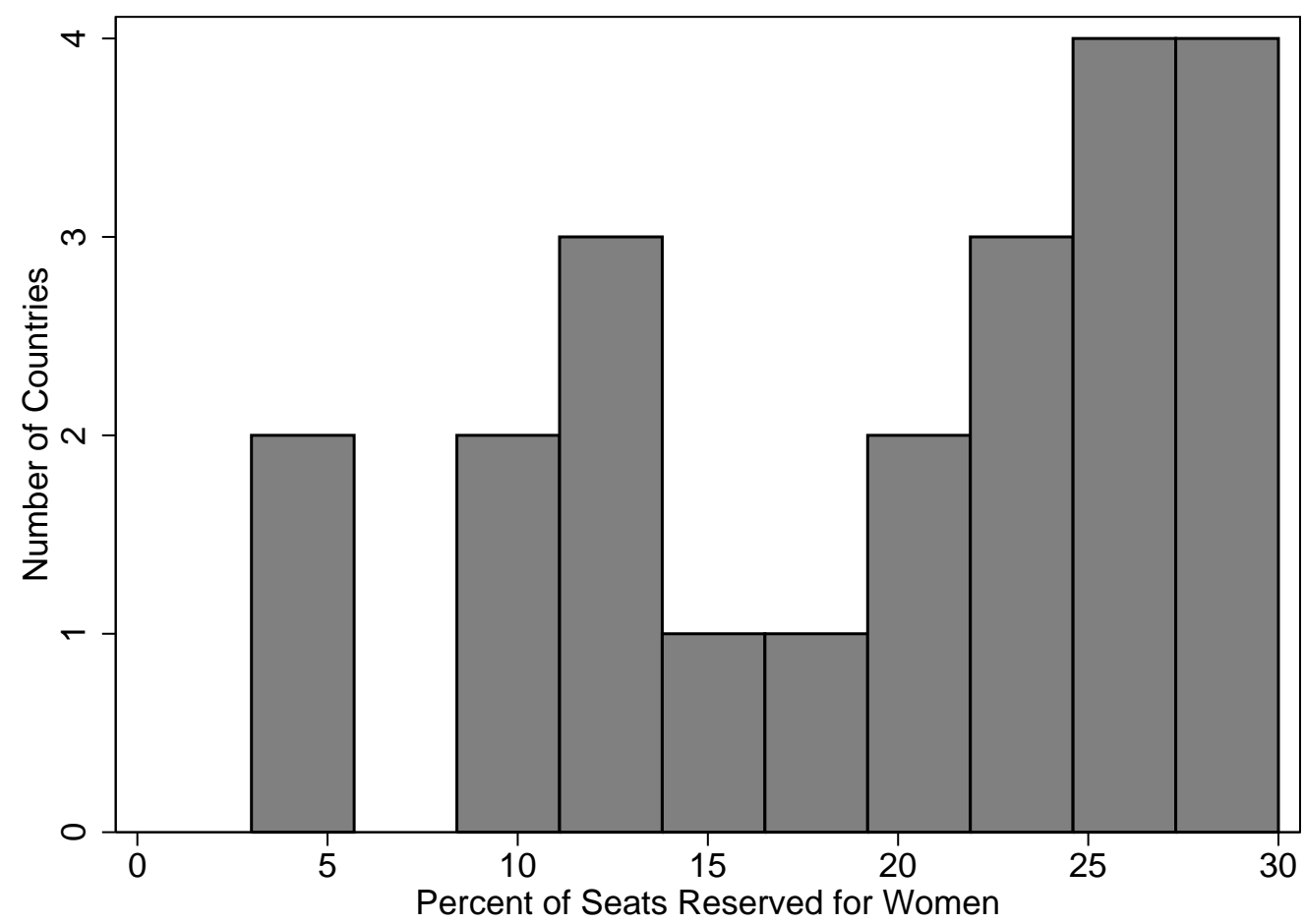

Notes: This histogram describes the quota size for each country which adopts a reserved seat quota. Each country (quota) is included as a single observation.

Source: authors' calculations based on data from Dahlerup (2005) and Global Database of Quotas for Women.

Table A1: Summary statistics for reserved seat analysis

\begin{tabular}{lccccc}
\hline & N & Mean & Std. Dev. & Min & Max \\
\hline \% Women in parliament & 4170 & 14.10 & 10.47 & 0.00 & 63.80 \\
Maternal mortality ratio & 4170 & 232.94 & 325.80 & 3.00 & 2890.00 \\
Reserved seats & 4170 & 0.06 & 0.23 & 0.00 & 1.00 \\
Male mortality rate (15-49) & 4084 & 238.38 & 117.23 & 58.80 & 688.96 \\
In(GDP per capita) & 4170 & 8.90 & 1.22 & 5.51 & 11.82 \\
Polity IV democracy score & 3211 & 5.60 & 3.86 & 0.00 & 10.00 \\
Percent of pregnancies receiving prenatal care & 659 & 84.10 & 17.84 & 15.40 & 100.00 \\
Percent of births attended by skilled staff & 1191 & 83.42 & 24.22 & 5.00 & 100.00 \\
Health expenditure as a percentage of GDP & 3139 & 6.23 & 2.39 & 0.72 & 17.10 \\
\hline
\end{tabular}

Notes: the MMR is measured as deaths per 100,000 live births. For comparison, the male mortality rate for 15-60-year-olds is expressed as per 1,000 male adults. Reserved seats is a binary variable taking 1 for each country and year pair where a quota was implemented, and 0 otherwise. Source: authors' calculations, based on data from the World Bank World Development Indicators, Dahlerup (2005), the Global Database of Quotas for Women, the Polity IV database, the World Bank Databank, and the World Health Organization Health Accounts database. See Appendix 2 for full details. 
Figure A5: Gender quotas: Event studies for women in parliament and maternal mortality without high-income countries: (a) percentage of women in parliament; (b) In(maternal mortality ratio)

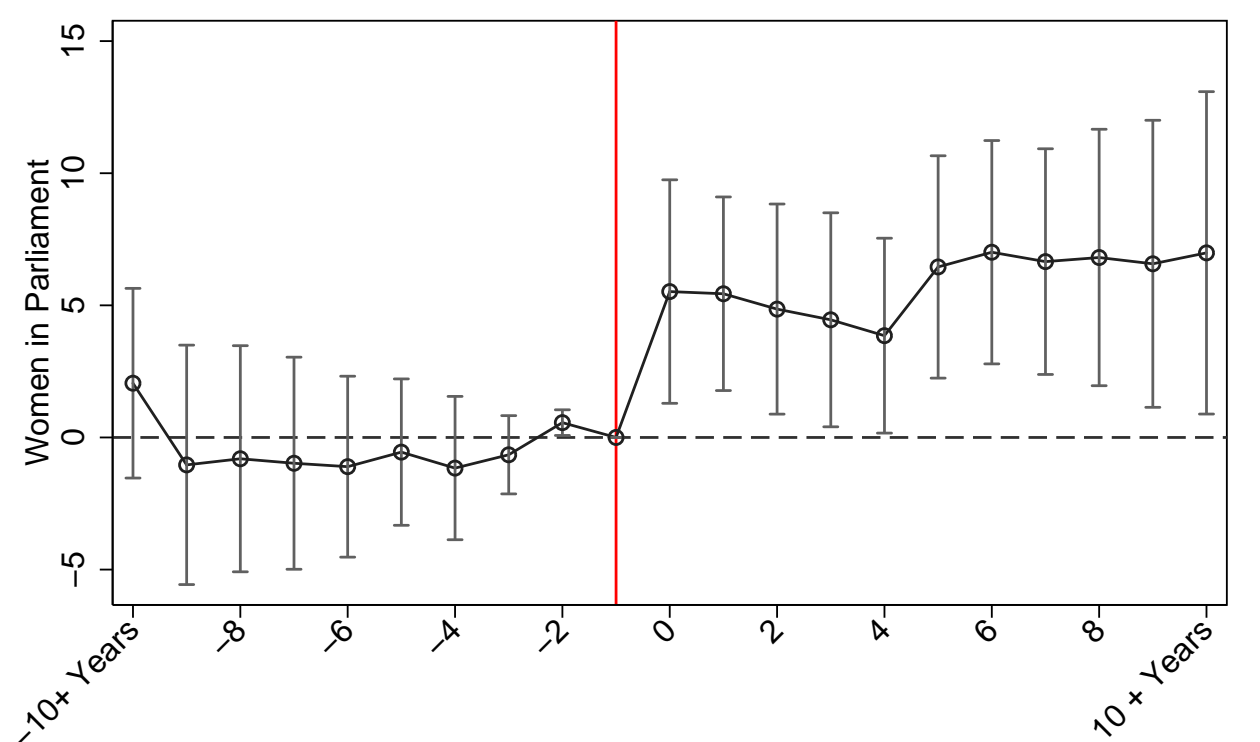

Time to Reform

○ Point Estimate $\longmapsto 95 \% \mathrm{Cl}$

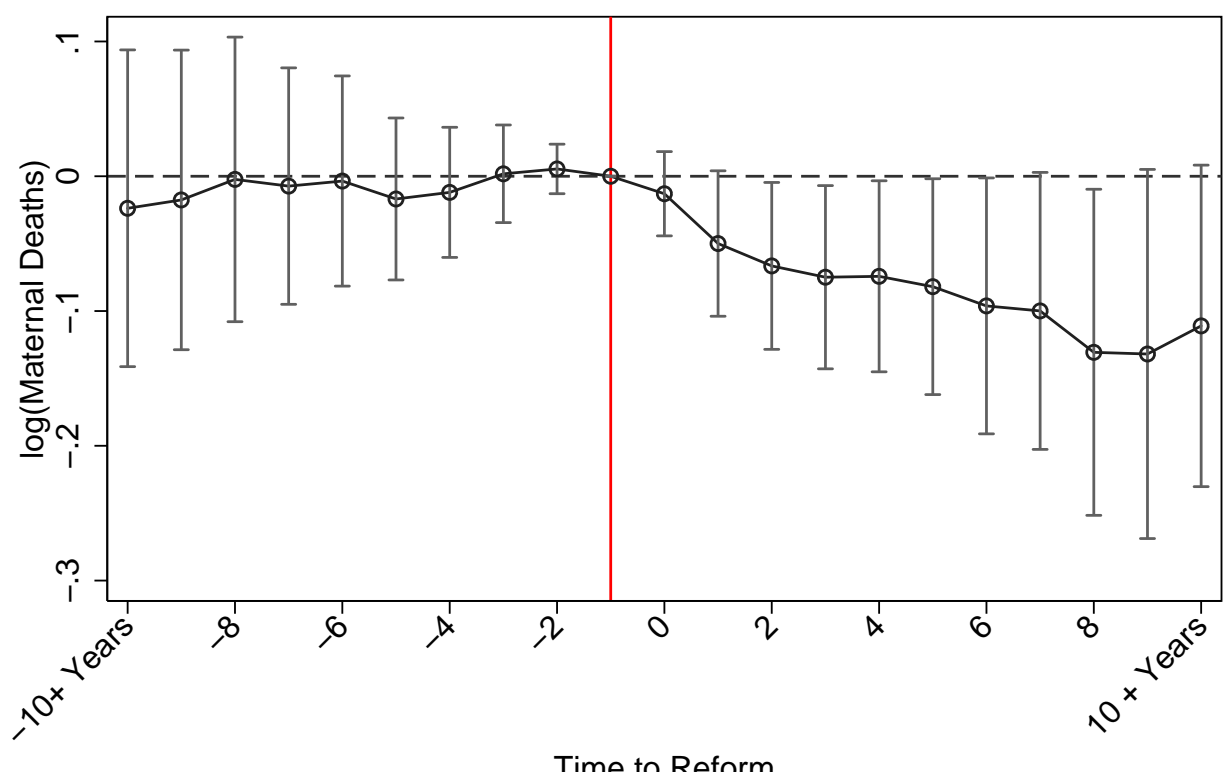

○ Point Estimate $\longmapsto 95 \% \mathrm{Cl}$

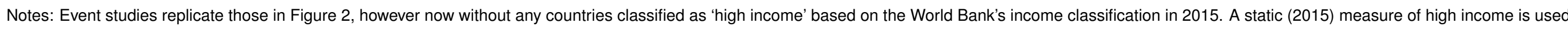
to ensure consistency of the sample across years. The estimation sample of non-high-income countries consists 2,309 yearly observations in 112 countries.

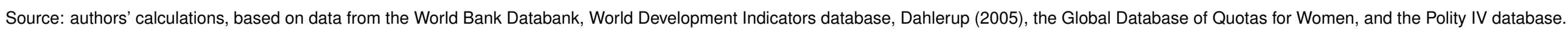


Table A2: Gender quotas: DD impacts on women in parliament and maternal mortality

\begin{tabular}{|c|c|c|c|c|c|c|c|c|c|}
\hline & \multicolumn{3}{|c|}{$\%$ Women in Parliament } & \multicolumn{3}{|c|}{ In(Maternal Mortality Ratio) } & \multicolumn{3}{|c|}{ Maternal Mortality Ratio } \\
\hline & (1) & (2) & (3) & (4) & (5) & (6) & (7) & (8) & (9) \\
\hline Reserved seats & $\begin{array}{c}4.911 \\
{[2.220]}\end{array}$ & $\begin{array}{c}5.544 \\
{[2.247]}\end{array}$ & $\begin{array}{c}5.849 \\
{[1.761]}\end{array}$ & $\begin{array}{l}-0.088 \\
{[0.050]}\end{array}$ & $\begin{array}{l}-0.093 \\
{[0.052]}\end{array}$ & $\begin{array}{l}-0.120 \\
{[0.068]}\end{array}$ & $\begin{array}{c}-102.169 \\
{[47.491]}\end{array}$ & $\begin{array}{c}-114.949 \\
{[48.218]}\end{array}$ & $\begin{array}{r}-106.907 \\
{[24.260]}\end{array}$ \\
\hline Mean of dep. var. & 13.647 & 13.632 & 13.632 & 4.397 & 4.389 & 4.389 & 249.190 & 249.707 & 249.707 \\
\hline Observations & 3212 & 3167 & 3167 & 3212 & 3167 & 3167 & 3212 & 3167 & 3167 \\
\hline Number of countries & 156 & 154 & 154 & 156 & 154 & 154 & 156 & 154 & 154 \\
\hline R-squared & 0.475 & 0.482 & 0.565 & 0.596 & 0.587 & 0.619 & 0.373 & 0.378 & 0.449 \\
\hline Population weights & $\mathrm{N}$ & $\mathrm{N}$ & Y & $\mathrm{N}$ & $\mathrm{N}$ & Y & $\mathrm{N}$ & $\mathrm{N}$ & Y \\
\hline
\end{tabular}

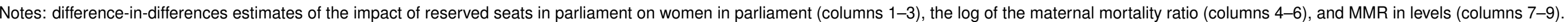

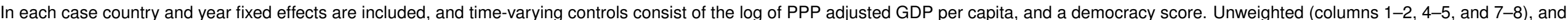

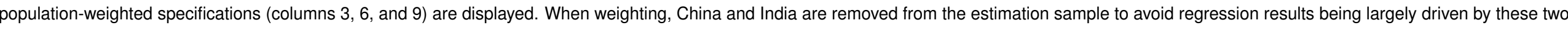
countries, with a population an order of magnitude larger than other countries. The unweighted specification without these countries is displayed in columns 2,5 , and 8.

Standard errors clustered by country are displayed in parentheses.

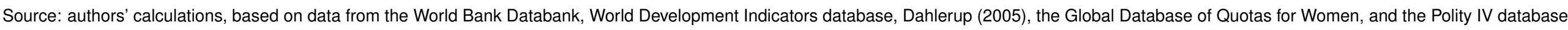


Figure A6: Proportion of women in parliament in countries with reserved seats

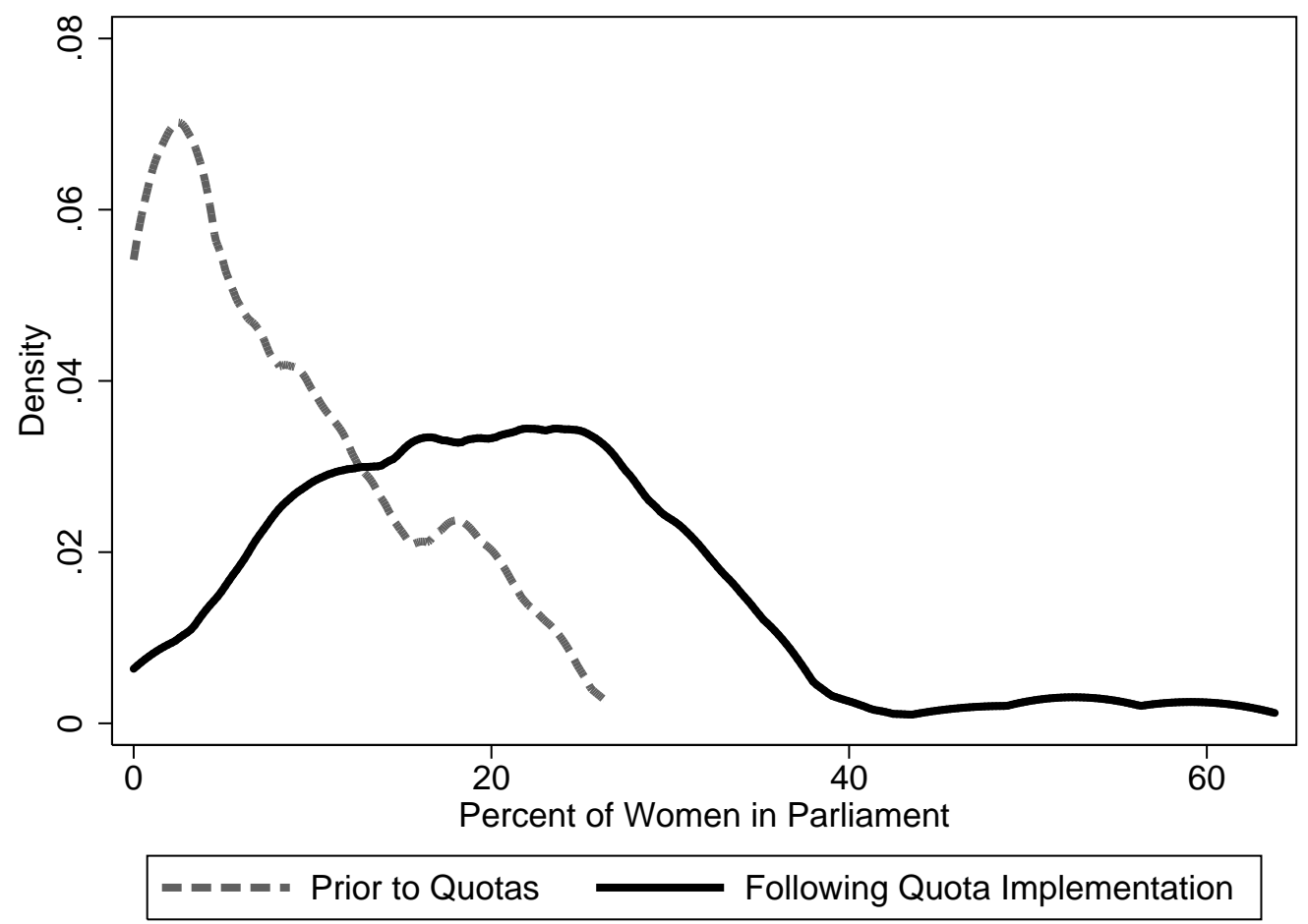

Notes: Density plots for the proportion of women in parliament in countries which at some point adopt a reserved seat quota. Plots are based on each country by year observation in the women in parliament data.

Source: authors' calculations, based on data from the World Bank Databank, World Development Indicators database, Dahlerup (2005), the Global Database of Quotas for Women, and the Polity IV database.

Figure A7: Proportion of women in parliament in all countries

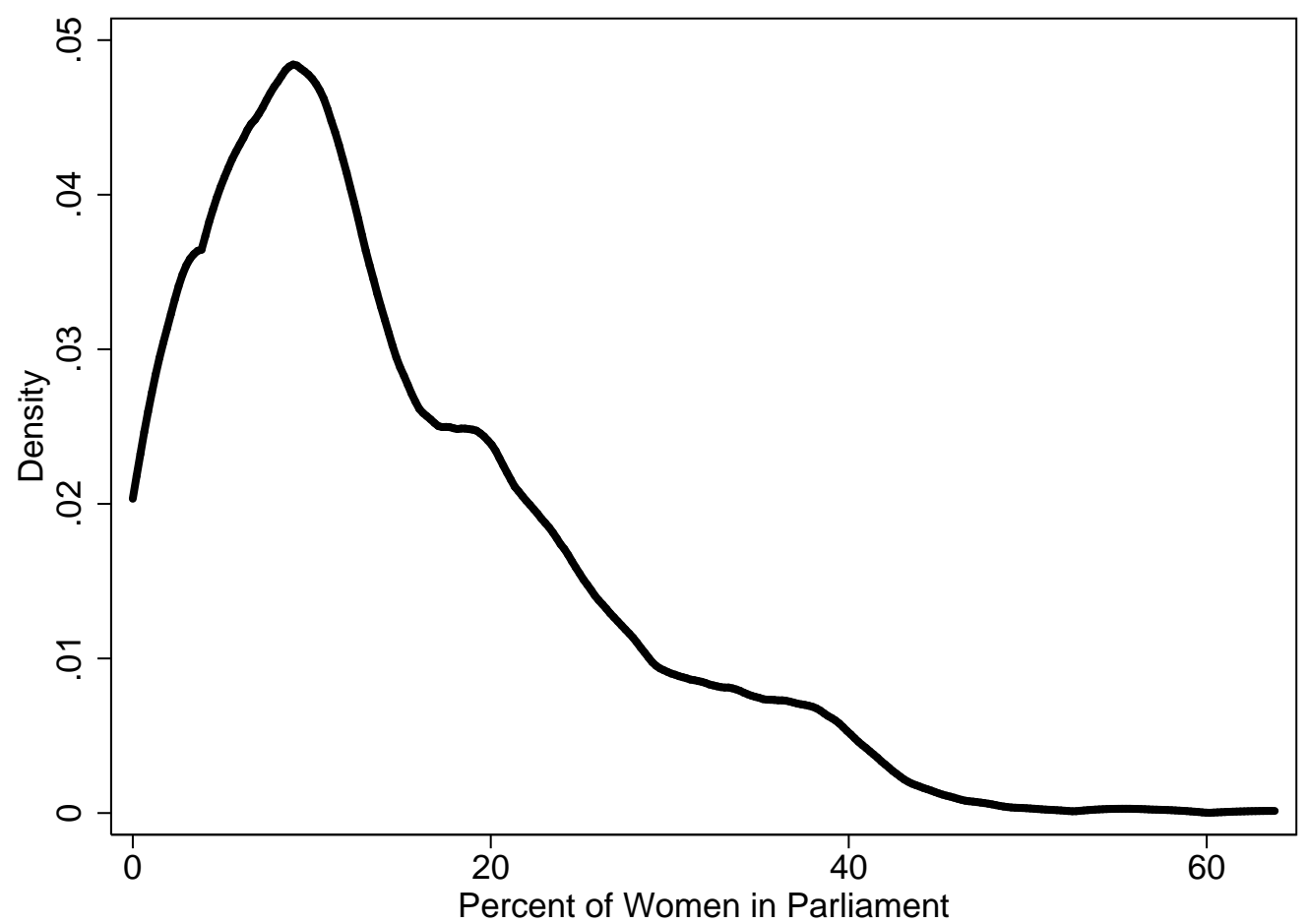

Notes: Density plots describe the proportion of women in parliament in all countries and years under study.

Source: authors' calculations, based on data from the World Bank World Development Indicators, Dahlerup (2005), and the Global Database of Quotas for Women. 

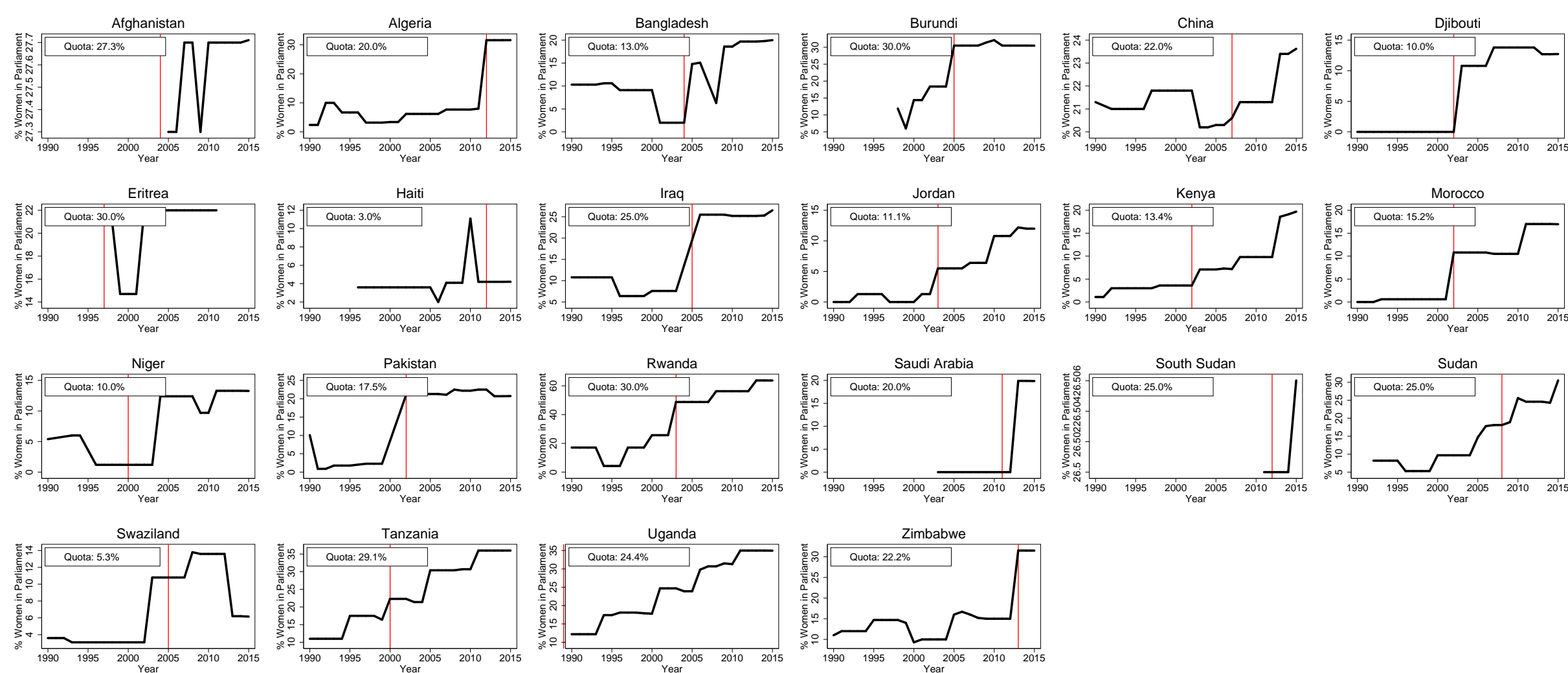

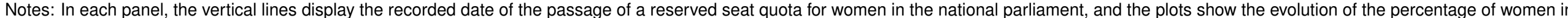
parliament.

Source: authors calculations, based on data from Dahlerup (2005), the Global Database of Quotas for Women, and the Polity IV database. 
Figure A9: Alternative specification of quota event study: (a) Women in parliament with no controls; (b) In(MMR) with no controls; (c) Women in parliament with GDP control only; (d) In(MMR) with GDP control only; (e) Women in parliament with democracy control only; (f) In(MMR) with democracy control only

(a)

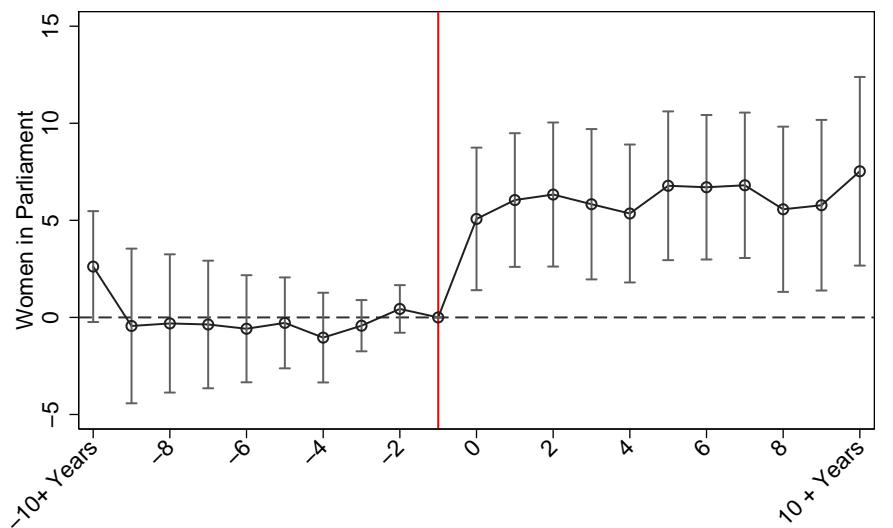

(b)

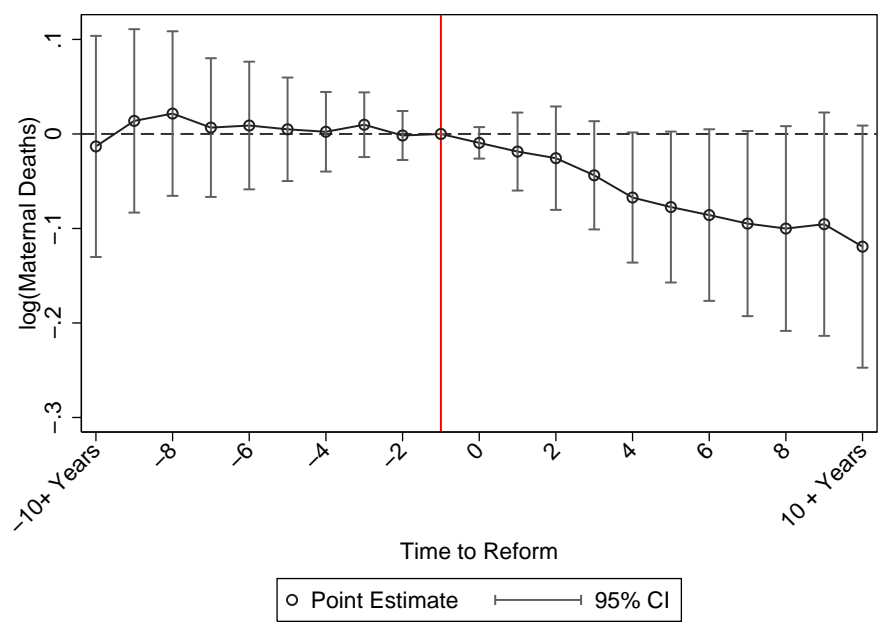

(d)

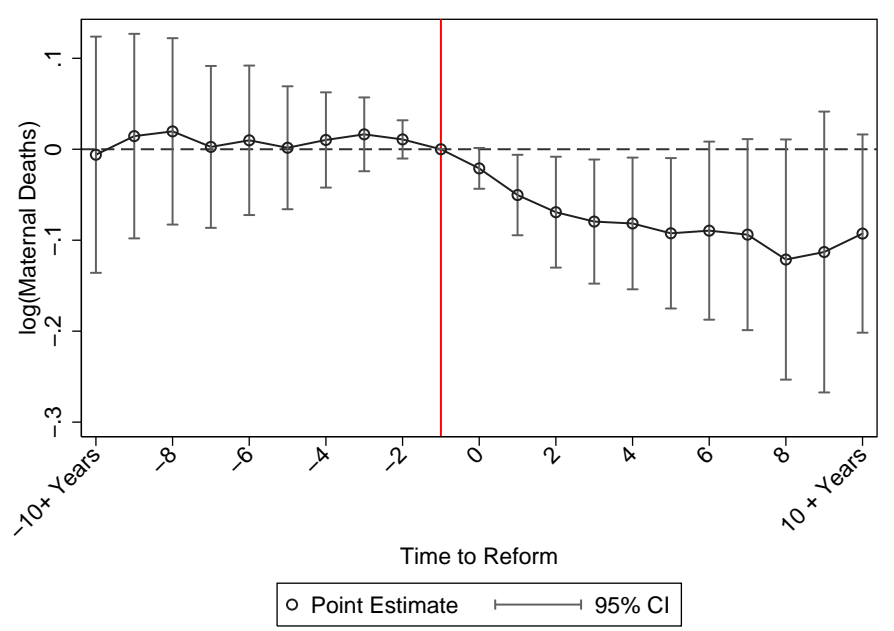

(f)

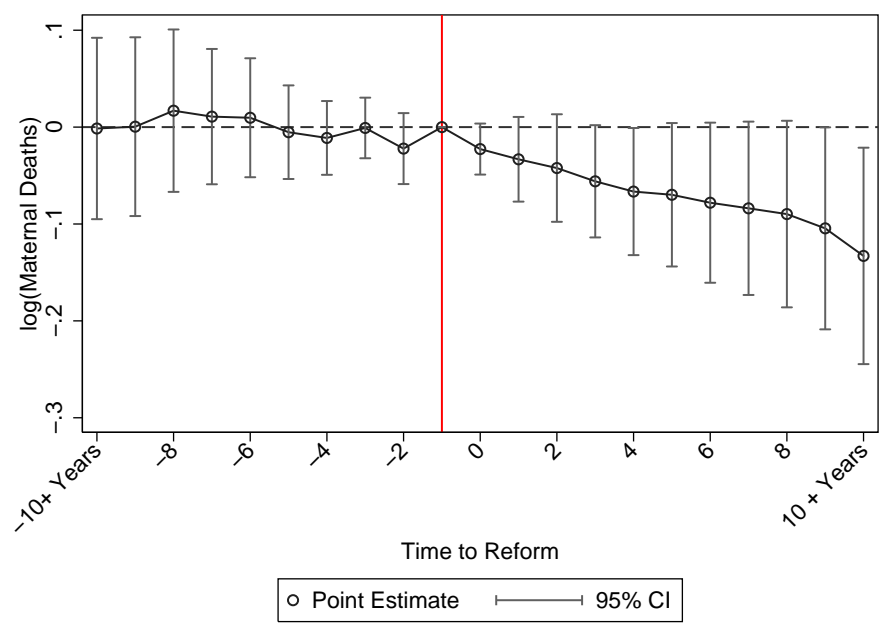

Notes: Alternative specifications of the event study shown in Figure 2. Specifications are shown with and without included controls, and with only GDP or only democracy controls. Results are robust to population weights, and additionally controlling for health spending per capita. Additional notes in Figure 2.

Source: authors' calculations, based on data from the World Development Indicators database, Dahlerup (2005), the Global Database of Quotas for Women, and the Polity IV database. 
Table A3: Intensive margin impacts of reserved seats (binned by quota size)

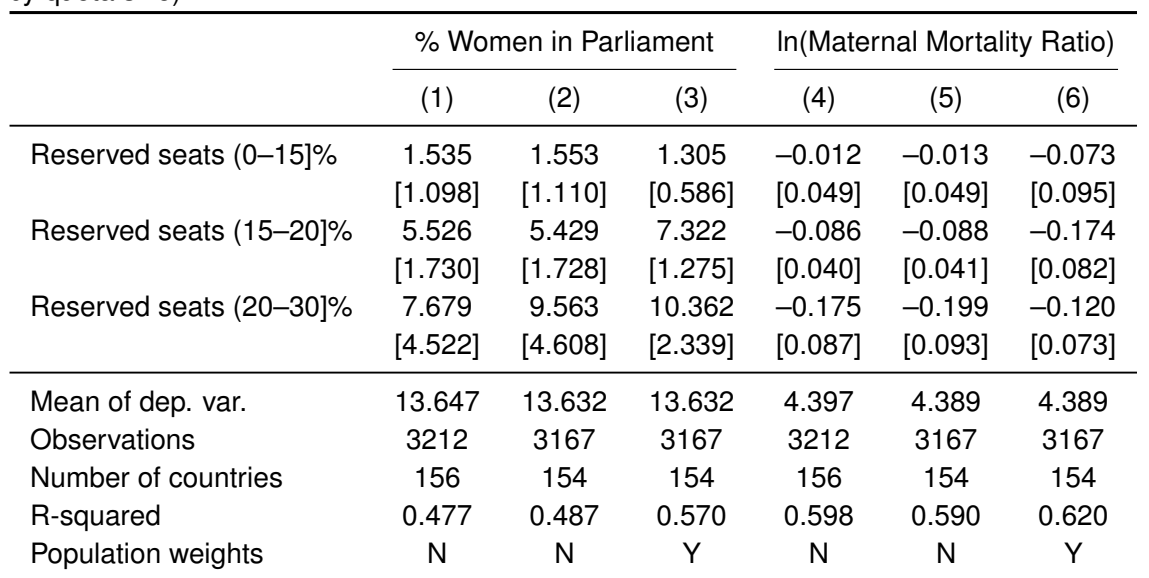

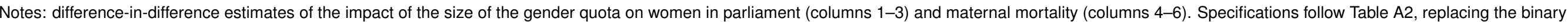

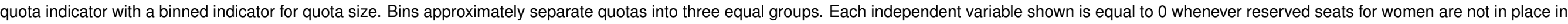
a country, and equal to 1 when a reserved seat quota is in place, and is of the magnitude indicated in the independent variable listed in the table. Remaining details are available as notes to Table A2.

Source: authors' calculations, based on data from the World Development Indicators database, Dahlerup (2005), the Global Database of Quotas for Women, and the Polity IV database. 
Table A4: Reserved seats as an IV for women in parliament

\begin{tabular}{lccc}
\hline & $\begin{array}{c}(1) \\
\text { In(MMR) }\end{array}$ & $\begin{array}{c}(2) \\
\text { In(MMR) }\end{array}$ & $\begin{array}{c}(3) \\
\text { In(MMR) }\end{array}$ \\
\hline \% Women in parliament & -0.018 & -0.017 & -0.021 \\
& {$[0.008]$} & {$[0.007]$} & {$[0.012]$} \\
\hline F-statistic first stage & 4.654 & 5.792 & 10.494 \\
$p$ value first stage & 0.033 & 0.017 & 0.001 \\
95 per cent Cl from Conley et al. (2012) & {$[-0.032 ;-0.001]$} & {$[-0.030 ;-0.002]$} & {$[-0.047 ; 0.054]$} \\
Mean of dep. var. & 4.397 & 4.389 & 4.389 \\
Observations & 3212 & 3167 & 3167 \\
Number of countries & 156 & 154 & 154 \\
Population weights & $\mathrm{N}$ & $\mathrm{N}$ & $\mathrm{Y}$ \\
\hline
\end{tabular}

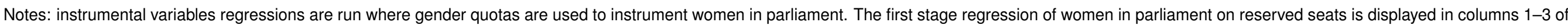

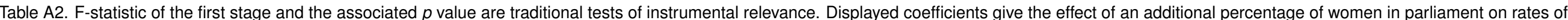

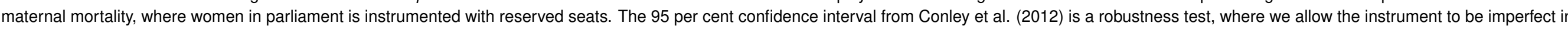

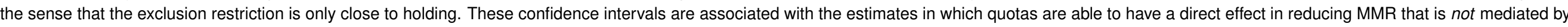

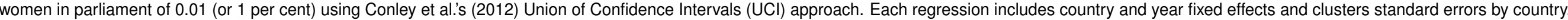

Source: authors' calculations, based on data from the World Development Indicators database, Dahlerup (2005), the Global Database of Quotas for Women, and the Polity IV database. 
Table A5: The passage of reserved seat legislation

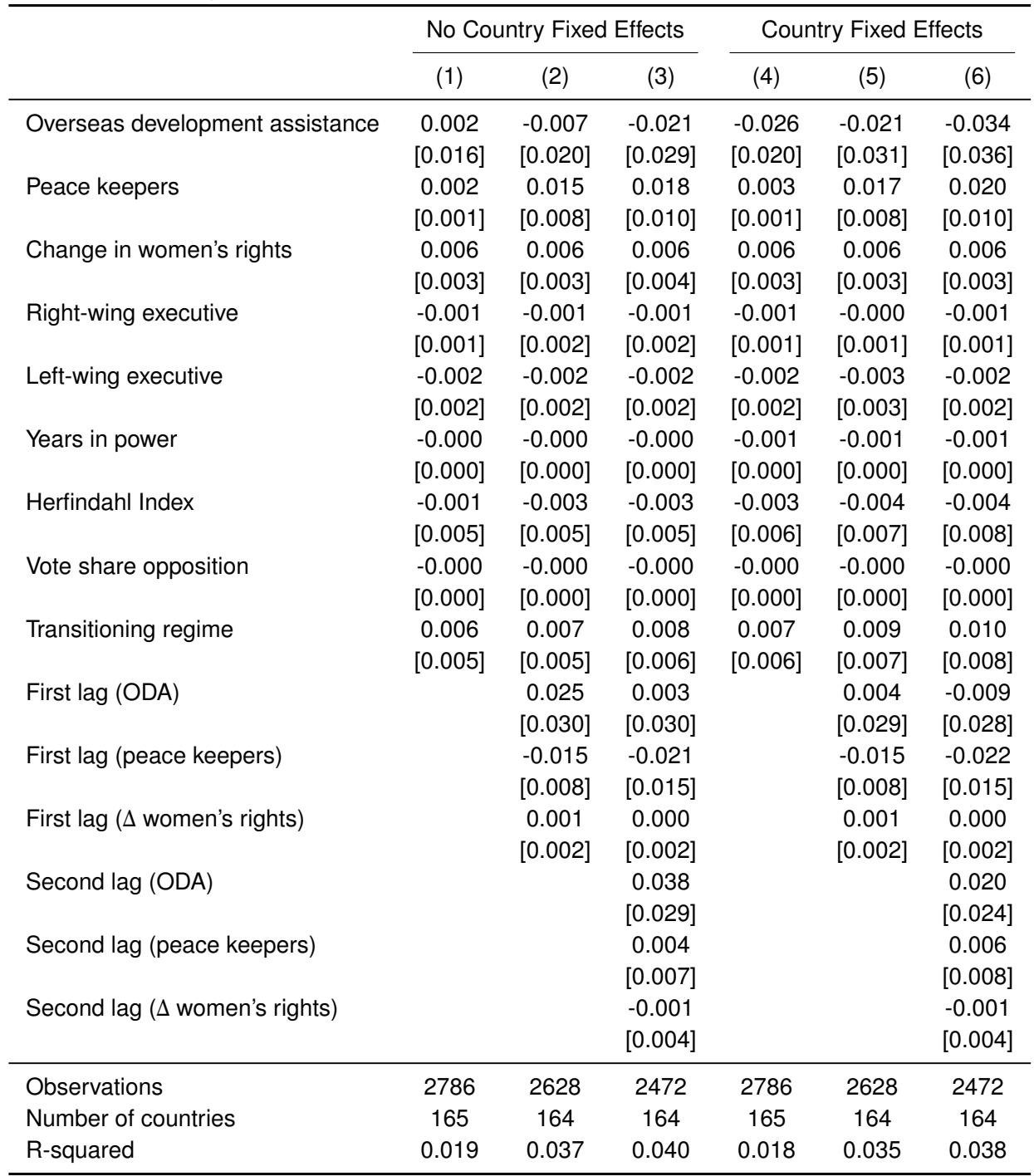

Notes: Each column regresses a variable indicating whether a quota law was passed in a given year on potential predictors of quota adoption suggested in the political science literature. Each specification includes year fixed effects and standard errors are clustered by country. Overseas development assistance (ODA) measured as net inflows in current US dollars divided by GDP in current US dollars is generated from the World Bank Data Bank. Peacekeepers (measured in thousands) are from the IPI Peacekeeping Database, changes in women's rights refer to changes in economic rights for women as compiled by the CIRI Human Rights Data Project, and political measures including the orientation of leader's party, the time in power, Herfindahl Index of parties, vote shares, and regime types and changes are recorded by the Database of Political Institutions. Additional lags of relevant variables are included in columns 2 and 3, and 5 and 6 .

Source: authors, based on the sources listed within the notes. 
Table A6: Estimates including all potential quota predictors

\begin{tabular}{|c|c|c|c|c|}
\hline & \multicolumn{2}{|c|}{ In(Maternal mortality ratio) } & \multicolumn{2}{|c|}{$\%$ Women in parliament } \\
\hline & (1) & (2) & (3) & (4) \\
\hline \multirow[t]{2}{*}{ Reserved seats } & -0.088 & -0.090 & 4.911 & 6.184 \\
\hline & {$[0.050]$} & [0.051] & [2.220] & [2.677] \\
\hline \multirow[t]{2}{*}{ Overseas development assistance } & & 0.079 & & -4.154 \\
\hline & & {$[0.080]$} & & [4.181] \\
\hline \multirow[t]{2}{*}{ Peace keepers } & & -0.002 & & 0.066 \\
\hline & & [0.002] & & {$[0.147]$} \\
\hline \multirow[t]{2}{*}{ Change in women's rights } & & 0.005 & & 0.227 \\
\hline & & [0.005] & & {$[0.187]$} \\
\hline \multirow[t]{2}{*}{ Right-wing executive } & & 0.013 & & -0.356 \\
\hline & & [0.021] & & {$[0.418]$} \\
\hline \multirow[t]{2}{*}{ Left-wing executive } & & -0.054 & & 0.429 \\
\hline & & {$[0.037]$} & & [0.605] \\
\hline \multirow[t]{2}{*}{ Years in power } & & 0.000 & & 0.084 \\
\hline & & {$[0.001]$} & & {$[0.037]$} \\
\hline \multirow[t]{2}{*}{ Herfindahl Index } & & -0.046 & & 1.083 \\
\hline & & [0.043] & & [1.178] \\
\hline \multirow[t]{2}{*}{ Vote share opposition } & & -0.001 & & -0.025 \\
\hline & & {$[0.000]$} & & [0.011] \\
\hline \multirow[t]{2}{*}{ Transitioning regime } & & -0.008 & & 1.020 \\
\hline & & [0.013] & & {$[0.457]$} \\
\hline \multirow[t]{2}{*}{ First lag (ODA) } & & 0.052 & & -1.565 \\
\hline & & [0.051] & & [2.349] \\
\hline \multirow[t]{2}{*}{ Second lag (ODA) } & & 0.011 & & 0.372 \\
\hline & & {$[0.074]$} & & [2.436] \\
\hline \multirow[t]{2}{*}{ First lag (peace keepers) } & & -0.000 & & -0.079 \\
\hline & & [0.003] & & [0.209] \\
\hline \multirow[t]{2}{*}{ Second lag (peace keepers) } & & -0.000 & & 0.019 \\
\hline & & {$[0.004]$} & & {$[0.180]$} \\
\hline \multirow[t]{2}{*}{ First lag ( $\Delta$ women's rights) } & & 0.006 & & 0.159 \\
\hline & & {$[0.006]$} & & {$[0.215]$} \\
\hline \multirow[t]{2}{*}{ Second lag ( $\Delta$ women's rights) } & & 0.001 & & 0.180 \\
\hline & & {$[0.005]$} & & {$[0.162]$} \\
\hline Observations & 3212 & 2347 & 3212 & 2347 \\
\hline Number of countries & 156 & 152 & 156 & 152 \\
\hline R-squared & 0.596 & 0.597 & 0.475 & 0.494 \\
\hline Proposed predictors & $\mathrm{N}$ & Y & $\mathrm{N}$ & Y \\
\hline
\end{tabular}

Notes: The regressions include country and year fixed effects and controls for log GDP and a democracy index. All potential predictors of quotas, described in Table A5, are included as controls.

Source: authors' calculations, based on sources listed in notes of Table A5. 
Table A7: Gender quotas: DD impacts on TB mortality and male mortality

\begin{tabular}{lcccccccc}
\hline & \multicolumn{3}{c}{$\ln ($ TB mortality $)$} & & \multicolumn{3}{c}{$\ln$ (Male mortality) } \\
\cline { 2 - 3 } \cline { 7 - 9 } & $(1)$ & $(2)$ & $(3)$ & & $(4)$ & $(5)$ & $(6)$ \\
\hline Reserved seats & 0.182 & 0.210 & 0.141 & & -0.034 & -0.035 & -0.018 \\
& {$[0.123]$} & {$[0.125]$} & {$[0.098]$} & & $0.055]$ & {$[0.058]$} & {$[0.057]$} \\
\hline Mean of dep. var. & 1.877 & 1.863 & 1.863 & & 5.391 & 5.394 & 5.394 \\
Observations & 3208 & 3163 & 3163 & & 3208 & 3163 & 3163 \\
Number of countries & 156 & 154 & 154 & & 156 & 154 & 154 \\
R-squared & 0.435 & 0.431 & 0.579 & & 0.496 & 0.492 & 0.588 \\
Population weights & $\mathrm{N}$ & $\mathrm{N}$ & $\mathrm{Y}$ & $\mathrm{N}$ & $\mathrm{N}$ & $\mathrm{Y}$ \\
\hline
\end{tabular}

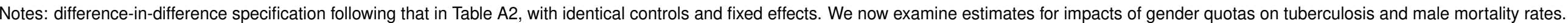

Tuberculosis is measured as incidence per 100,000 people, and male mortality is measured as per 1,000 adult males. Further notes are available in Table A2.

Standard errors clustered by country are displayed in parentheses.

Source: authors' calculations, based on data from the World Bank Databank, Dahlerup (2005), the Global Database of Quotas for Women, and the Polity IV database. 
Figure A10: Gender quotas: event studies for women in parliament and maternal mortality controlling: (a) percentage of women in parliament; (b) In(maternal mortality ratio)

(a)

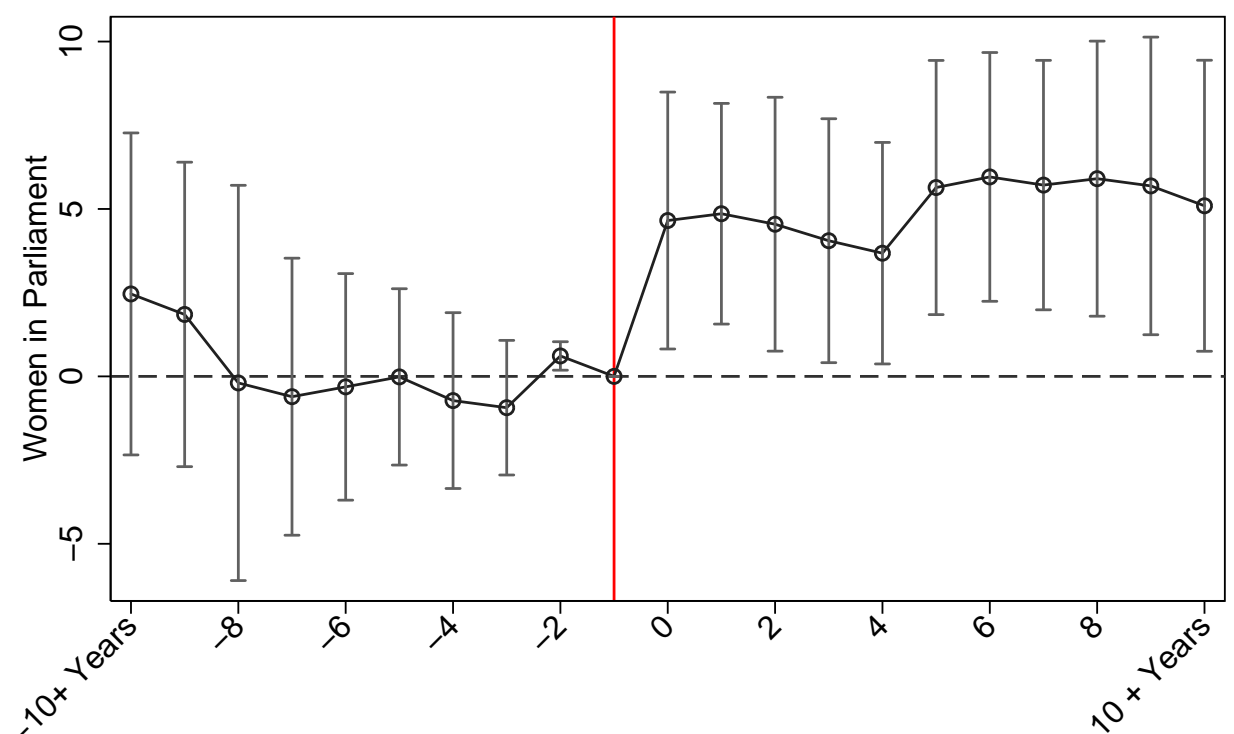

Time to Reform

o Point Estimate $\longmapsto 95 \% \mathrm{Cl}$

(b)

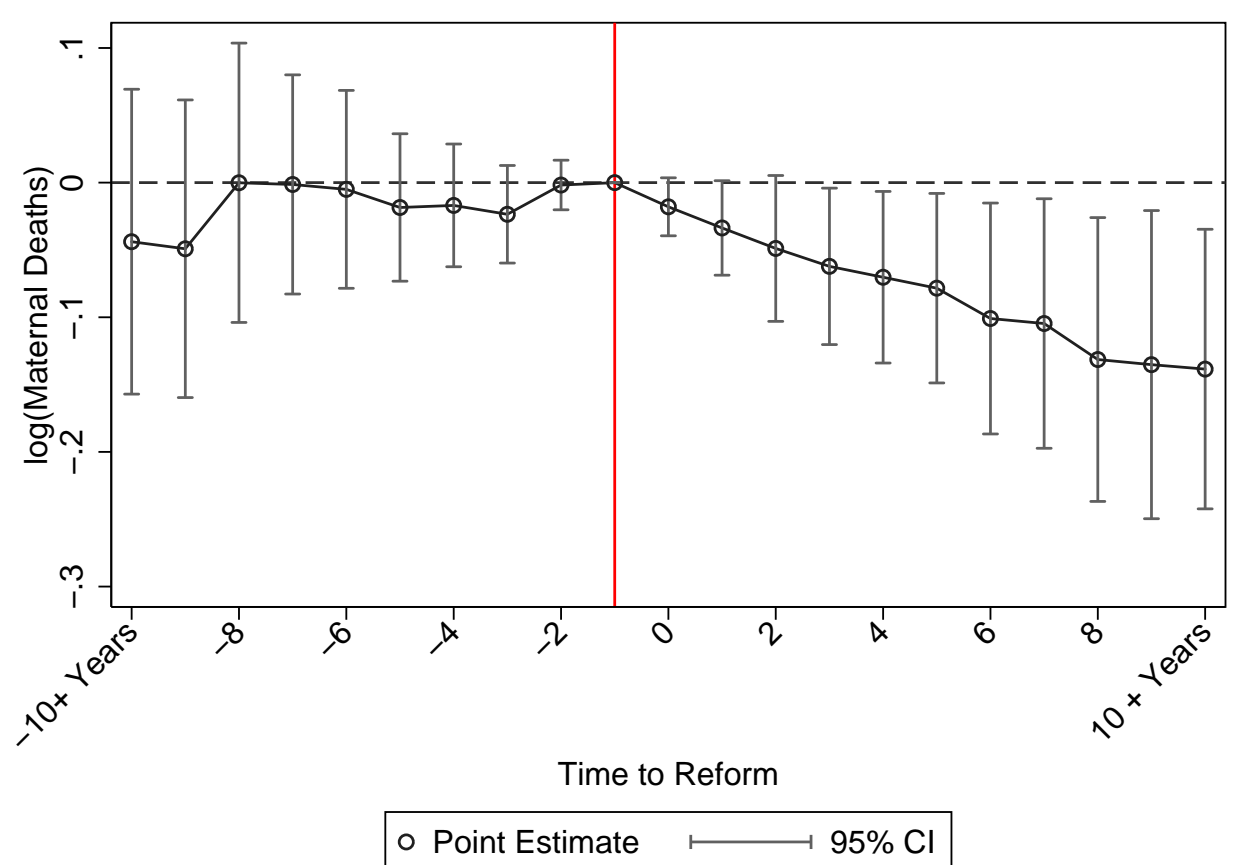

Notes: Event studies replicate Figure 2, controlling for the time-varying measure of health spending as a proportion of GDP per-capita.

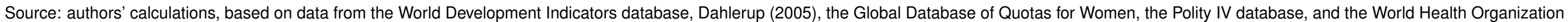
Health Accounts database. 


\begin{tabular}{|c|c|c|c|c|c|c|c|c|c|}
\hline & \multicolumn{3}{|c|}{ Antenatal Care } & \multicolumn{3}{|c|}{ Attended Births } & \multicolumn{3}{|c|}{ Health Spending } \\
\hline & (1) & (2) & (3) & (4) & (5) & (6) & (7) & (8) & (9) \\
\hline Reserved seats & $\begin{array}{c}4.661 \\
{[3.383]}\end{array}$ & $\begin{array}{c}7.414 \\
{[3.055]}\end{array}$ & $\begin{array}{c}9.184 \\
{[2.523]}\end{array}$ & $\begin{array}{c}6.374 \\
{[3.148]}\end{array}$ & $\begin{array}{c}8.819 \\
{[2.843]}\end{array}$ & $\begin{array}{c}7.746 \\
{[2.275]}\end{array}$ & $\begin{array}{c}0.626 \\
{[0.468]}\end{array}$ & $\begin{array}{c}0.624 \\
{[0.498]}\end{array}$ & $\begin{array}{l}-0.277 \\
{[0.323]}\end{array}$ \\
\hline Mean of dep. var. & 82.673 & 82.641 & 82.641 & 83.024 & 82.964 & 82.964 & 6.132 & 6.157 & 6.157 \\
\hline Observations & 526 & 500 & 500 & 996 & 970 & 970 & 2586 & 2550 & 2550 \\
\hline Number of countries & 134 & 132 & 132 & 149 & 147 & 147 & 155 & 153 & 153 \\
\hline R-squared & 0.506 & 0.521 & 0.721 & 0.360 & 0.370 & 0.687 & 0.226 & 0.227 & 0.452 \\
\hline Population weights & $\mathrm{N}$ & $\mathrm{N}$ & Y & $\mathrm{N}$ & $\mathrm{N}$ & $\mathrm{Y}$ & $\mathrm{N}$ & $\mathrm{N}$ & Y \\
\hline
\end{tabular}

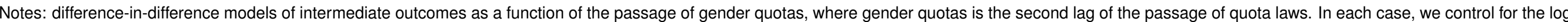

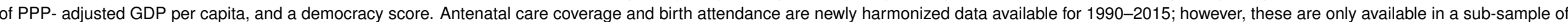

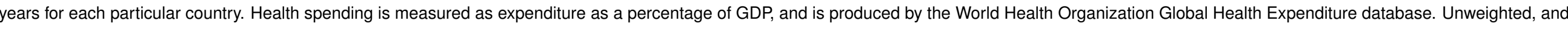

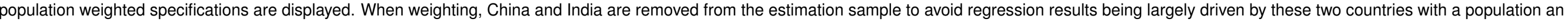
order of magnitude larger than other countries.

Source: authors, based on the sources listed above and in the notes for Table A7. 


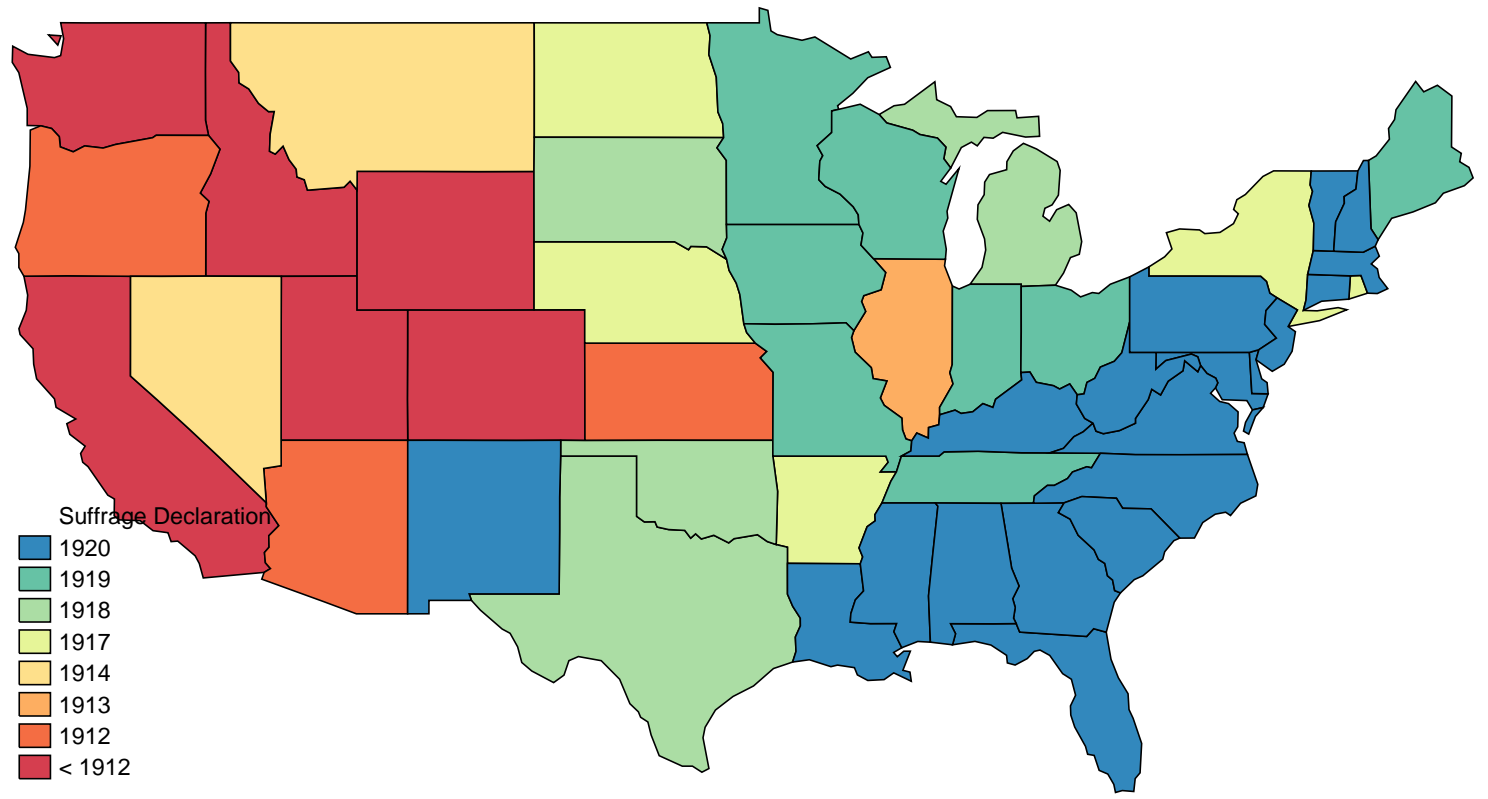

States declaring suffrage in 1920 with the passing of the Nineteenth Amendment (dark blue color) are 'late suffrage' states.

Source: Suffrage data is from Miller (2008).

Table A9: Early suffrage and subsequent female representation

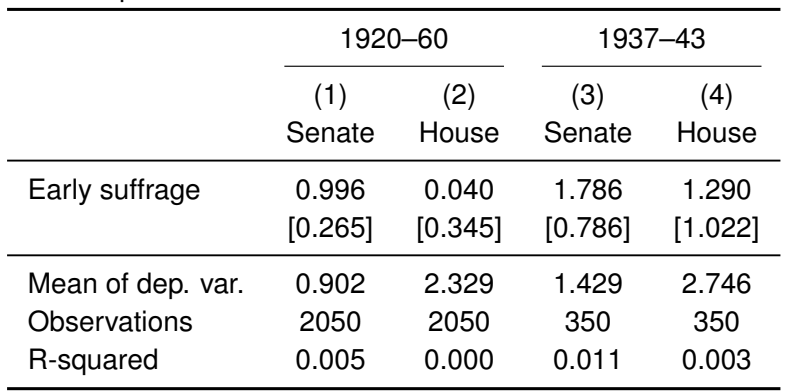

Notes: we display the coefficients of a regression of the percentage of a state's representatives in the National Senate and House of

Representatives on the state's suffrage status (early versus late). The percentage of representation is a value from 0 to 100 , and is calculated as the number of female representatives of a state in a given year divided by the total number of seats assigned to the state, multiplied by 100 . For example, column 3 shows that in the 1920-60 period, states adopting suffrage early went on to have nearly 1.8 percentage-points more women representatives in the Senate than states which adopted in 1920. The left-hand columns are for the entire post-suffrage period up until 1960, and the right-hand columns are for post-antibiotic period under study in this paper, 1937-43.

Source: authors' calculations, based on data from Manning and Brudnick (2018) and Miller (2008).

Table A10: Summary statistics for suffrage/sulfa analysis

\begin{tabular}{lccccc}
\hline & $\mathrm{N}$ & Mean & Std. dev. & Min. & Max. \\
\hline Maternal mortality ratio & 868 & 539.57 & 206.35 & 70.00 & 1210.00 \\
Infant pneumonia mortality ratio & 868 & 102.58 & 34.46 & 36.24 & 236.48 \\
Year of birth & 868 & 1934.37 & 5.34 & 1925.00 & 1943.00 \\
Post-sulfa & 868 & 0.39 & 0.49 & 0.00 & 1.00 \\
Early suffrage adopter & 868 & 0.60 & 0.49 & 0.00 & 1.00 \\
Female labour force participation rate & 868 & 0.29 & 0.07 & 0.17 & 0.40 \\
\hline
\end{tabular}

Notes: Maternal mortality ratio and infant pneumonia mortality ratio are measured as deaths per 100,000 live births. Sulfa drugs arrived in the United States in 1937, and post-sulfa takes the value of 1 in all years including and following 1937. The analysis sample consists of all years in the period 1925-43.

Source: authors' calculations, based on data from US Vital Statistics (via Jayachandran et al. 2010), Miller (2008), and the 1930 US Population Census (labour force participation). 
Figure A12: Suffrage and subsequent women representatives in national legislature: (a) Percentage of women in the senate; (b) Percentage of women in the house of representatives

(a)

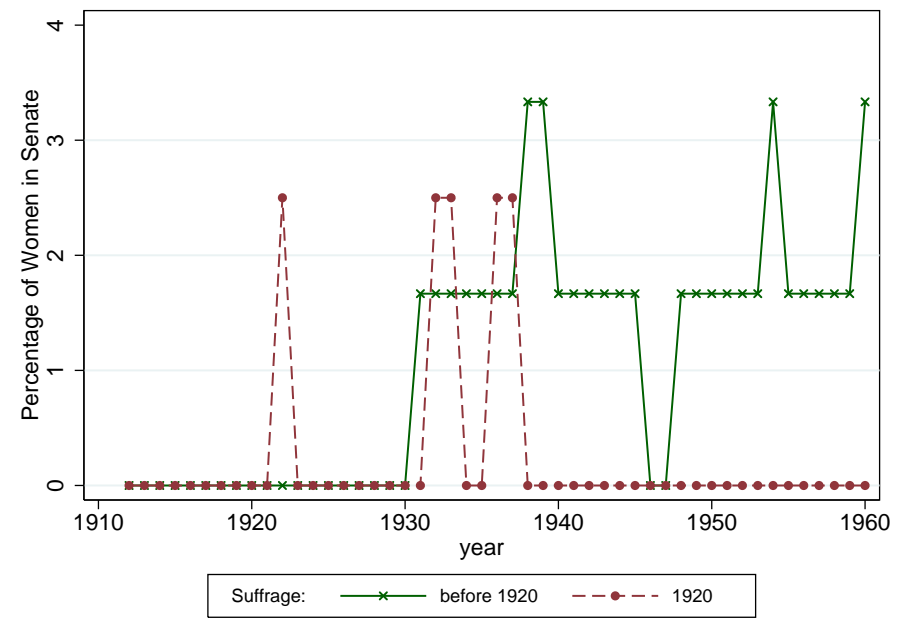

(b)

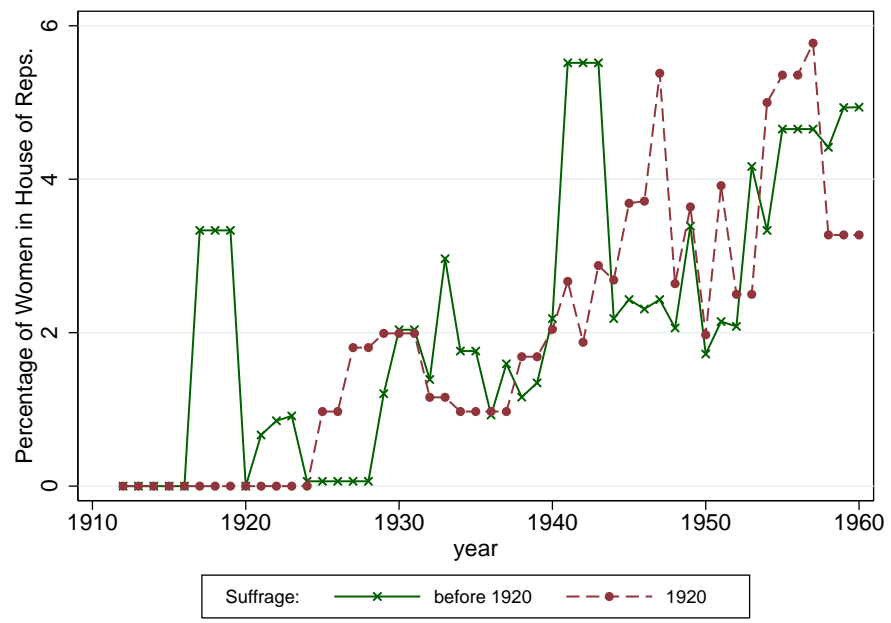

Notes: plots depict the percentage of female representatives in the National Senate (left-hand panel) and National House of Representatives of the USA from 1912 to 1960 for each of the early (pre-Nineteenth Amendment) and late (post-Nineteenth Amendment) states.

Source: authors' calculations, based on data from Manning and Brudnick (2018) and Miller (2008). 
Table A11: DD estimates: early adopters of suffrage had faster MMR decline in the post-antibiotic era

\begin{tabular}{|c|c|c|c|c|}
\hline & \multicolumn{2}{|c|}{ In(Maternal mortality ratio) } & \multicolumn{2}{|c|}{$\ln ($ pneumonia mortality) } \\
\hline & (1) & (2) & (3) & (4) \\
\hline \multirow[t]{2}{*}{ Post-sulfa } & -0.092 & -0.097 & 0.009 & 0.011 \\
\hline & {$[0.030]$} & {$[0.029]$} & [0.022] & [0.022] \\
\hline \multirow{2}{*}{ Early suffrage $\times$ Post Sulfa } & -0.085 & -0.046 & -0.046 & -0.060 \\
\hline & {$[0.036]$} & [0.041] & {$[0.028]$} & {$[0.031]$} \\
\hline \multirow[t]{2}{*}{ Early suffrage $\times$ Post Sulfa $\times$ Time } & -0.015 & -0.019 & -0.007 & -0.012 \\
\hline & {$[0.006]$} & [0.012] & [0.013] & [0.011] \\
\hline \multirow[t]{2}{*}{ Early suffrage $\times$ Time } & 0.001 & -0.002 & 0.005 & 0.008 \\
\hline & [0.003] & [0.003] & [0.008] & {$[0.006]$} \\
\hline \multirow[t]{2}{*}{ Time } & -0.023 & -0.024 & -0.029 & -0.024 \\
\hline & [0.002] & [0.002] & {$[0.006]$} & {$[0.005]$} \\
\hline \multirow[t]{2}{*}{ Post-sulfa $\times$ Time } & -0.089 & -0.090 & -0.061 & -0.069 \\
\hline & {$[0.005]$} & {$[0.008]$} & {$[0.011]$} & {$[0.008]$} \\
\hline \multirow[t]{2}{*}{ Constant } & 6.294 & 6.307 & 4.559 & 4.618 \\
\hline & [0.012] & {$[0.011]$} & {$[0.015]$} & [0.015] \\
\hline Mean of dep. var. & 6.206 & 6.206 & 4.573 & 4.573 \\
\hline Observations & 868 & 868 & 868 & 868 \\
\hline R-squared & 0.951 & 0.906 & 0.780 & 0.757 \\
\hline State population weights & $\mathrm{Y}$ & $\mathrm{N}$ & $\mathrm{Y}$ & $\mathrm{N}$ \\
\hline
\end{tabular}

Notes: the estimation sample consists of state by year mortality data from 1925 to 1943 (inclusive). Each regression includes state and year fixed effects and clusters standard errors by state. Source: authors' calculations, based on data from US Vital Statistics (via Jayachandran et al. 2010) and Miller (2008). 
Figure A13: Alternative specification of sulfa/suffrage event study: (a) In(MMR) weighted by state population; (b) In(IPR) weighted by state population; (c) In(MMR) with balanced sample only; (d) In(IPR) with balanced sample only; (e) In(MMR) with FLFP controls and trends; (f) In(IPR) with FLFP controls and trends

(a)

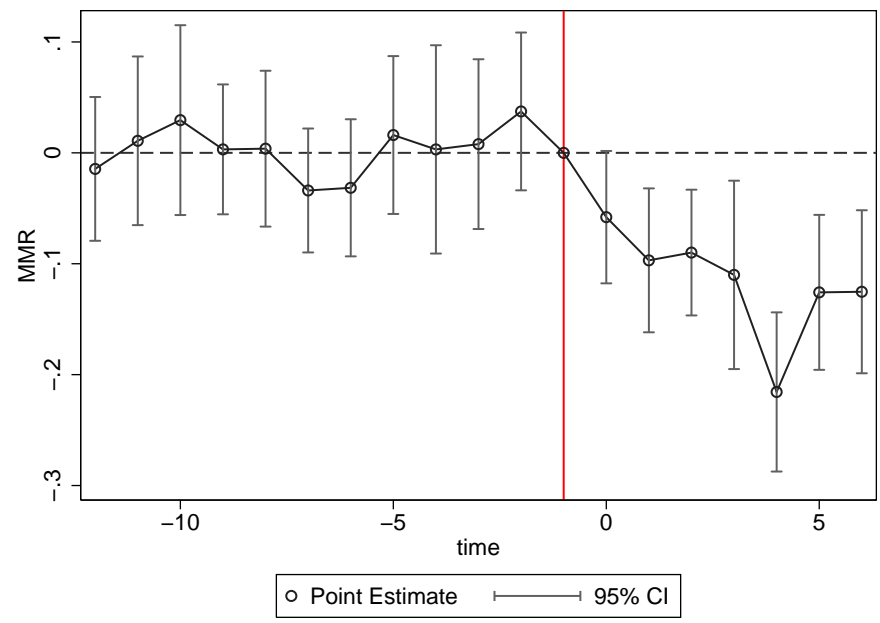

(c)

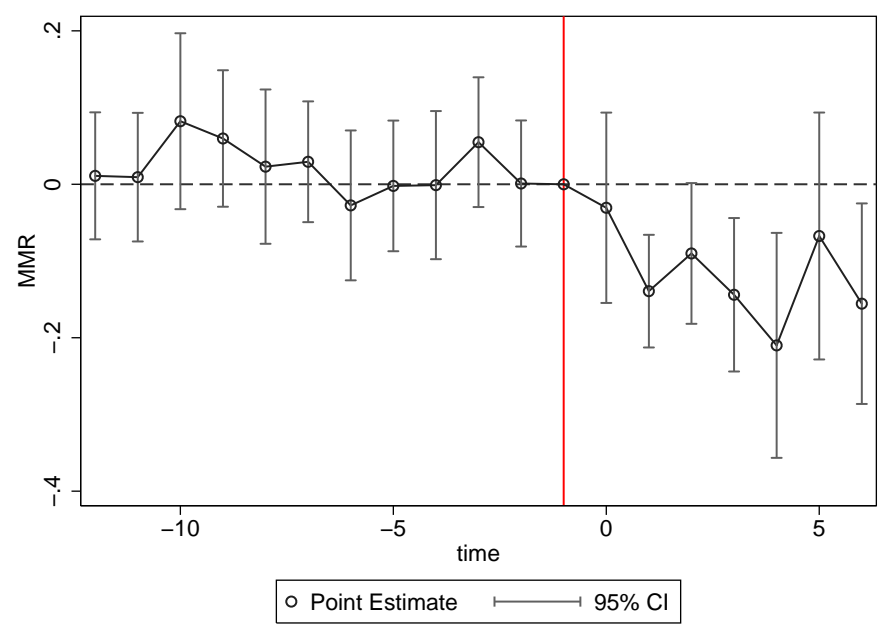

(e)

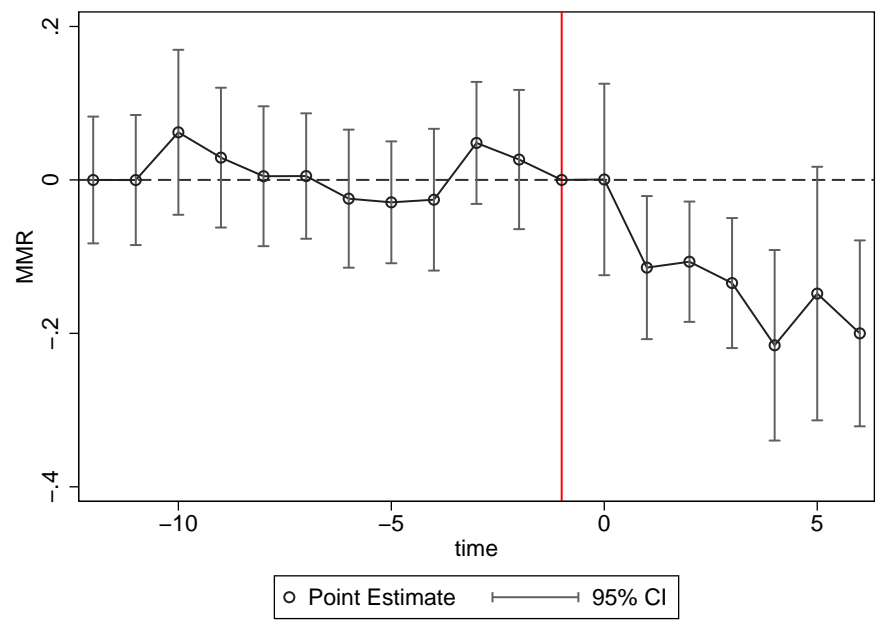

(b)

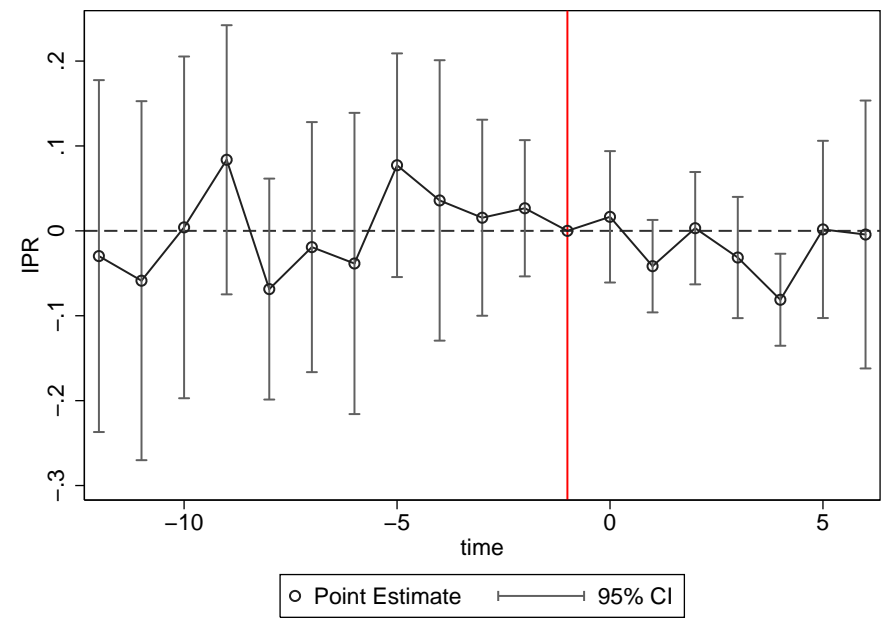

(d)

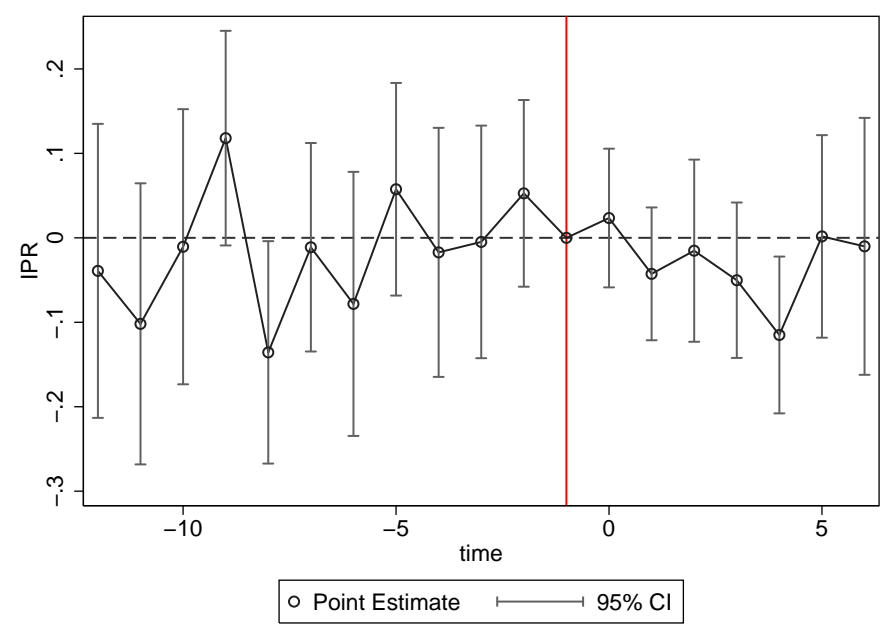

(f)

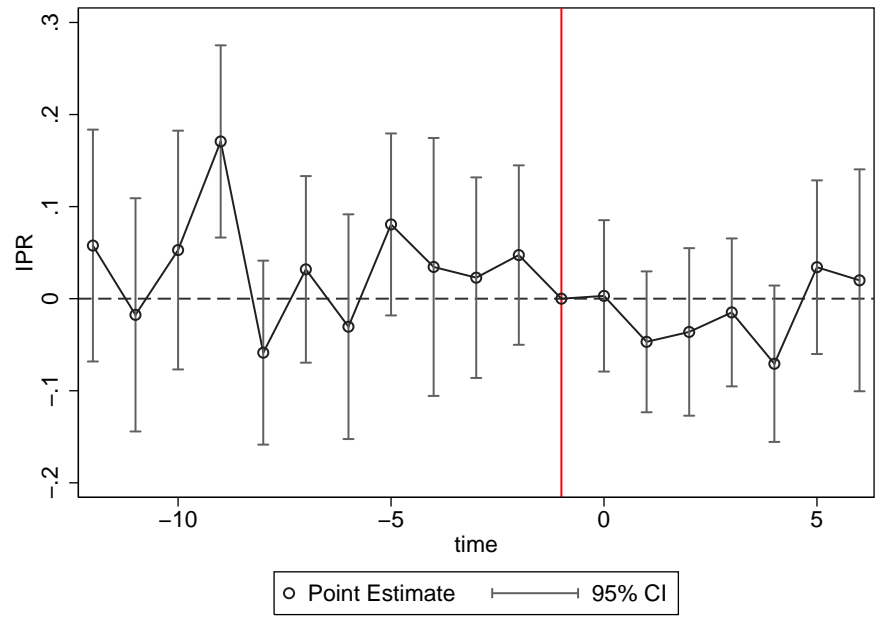

Notes: Alternative specifications of the event study shown in Figure 4. The balanced sample refers to states with mortality data in all years under study, and the final two figures augment the event study specification in equation 2 with the following controls and interactions to capture any differences in baseline women's labour force participation: a post sulfa times FLFP interaction Post $1937_{t} \times F L F P_{s}$, an interaction between FLFP and time, year $_{t} \times F L F P_{S}$ and an interaction between FLFP, time, and post sulfa Post $1937_{t} \times$ year $_{t} \times F L F P_{S}$.

Source: authors' calculations, based on data from US Vital Statistics (via Jayachandran et al. 2010) and Miller (2008). 
Maternal mortality data. We used recently released estimates of the maternal mortality ratio (MMR) per 100,000 live births produced by the Maternal Mortality Estimation Inter-Agency Group (MMEIG) and published in the World Bank World Development Indicators (WDI, indicator SH.STA.MMRT). These data were made available for the first time in 2016 and before that there were no reliable annual cross-country data on MMR. These estimates were available for 183 countries annually for the period 1990-2015. Maternal mortality is identified using ICD-10 codes O00-O99 (pregnancy, childbirth and puerperium); the official definition is 'the number of women who die from pregnancy-related causes while pregnant or within 42 days of pregnancy termination per 100,000 live births.' These are widely considered the best MMR measures to date, as they address known measurement difficulties in survey and vital statistics data on maternal mortality using Bayesian methods applied to multiple, complementary data sources including vital statistics, special inquiries, surveillance sites, population-based household surveys and census files (Alkema et al. 2016, 2017). The world distribution of average MMR for the period 1990-2015 is in Figure A14.

Figure A14: Maternal mortality ratio: 1990-2015

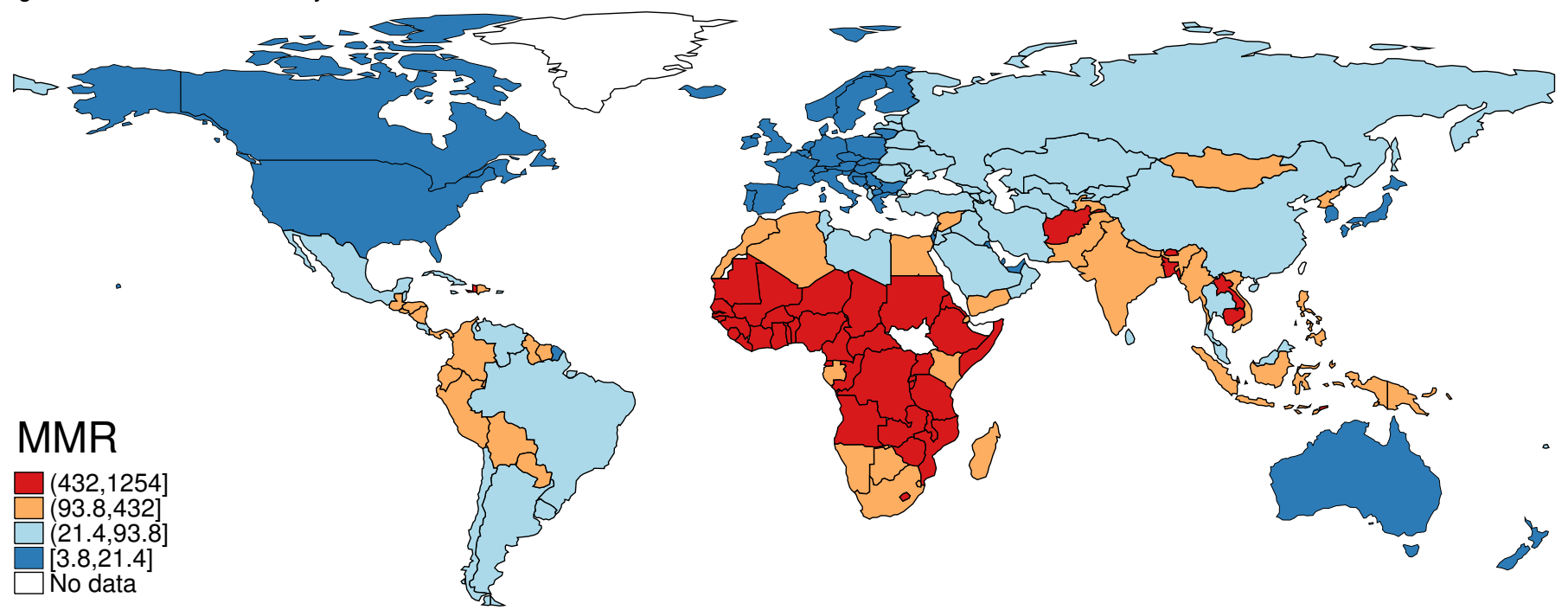

Notes: average rates by country for the period 1990-2015. Values are calculated as deaths per 100,000 live births

Source: values are provided by WHO, UNICEF, UNFPA, World Bank Group, and the United Nations Population Division.

Political gender quota data. We collated measures for each country of whether the country has a legislated and binding reserved seat quota for women, its year of implementation, and the size of the quota measured as number of seats divided by all seats in the uni- or bi-cameral chamber. To create the database, we started with measures provided by Dahlerup (2005) and completed the most recent years from Global Database of Quotas for Women database (available online at quotaproject.org), which is a repository developed and maintained by the International Institute for Democracy and Electoral Assistance (IDEA), the Inter-Parliamentary Union, and Stockholm University.

Women in parliament data. We used three distinct annual-level measures of women in parliament to construct a comprehensive panel of the percentage of women occupying seats in the national parliament. These were the WDI indicator SG.GEN.PARL.ZS ('Proportion of seats held by women in national parliaments (\%)'), the UN Millennium Development Goals (MDG) Indicators ('Seats held by women in national parliament, percentage'), and the Interuniversity Consortium for Political and Social Research (ICPSR) dataset compiled by (Paxton et al. 2008) ('Women in Parliament, 1945-2003: Cross-National Dataset'). The first two of these datasets had partially complete coverage for the years 1990, and then 1997-2015, while the latter had partially-complete yearly coverage for each year starting in 1945, and ending in 2003. In order to construct as comprehensive a series as possible, we began with the WDI data, and then imputed missing years where available from the MDG indicators, and Paxton et al. (2008) data. When a missing WDI year was available in both the MDG and the ICPSR dataset, we favoured the MDG measure, which was estimated using the same sample and year. Figures A6 and A7 present the distribution of the proportion of women in parliament pre- and post-quota implementation in quota countries, as well as the full distribution of the proportion of women in parliament over the period under study.

Covariates. We adjusted for the natural logarithm of PPP-adjusted GDP per capita measured in 2011 international dollars, and a score for the level of democracy in the country, in all models. In additional sensitivity tests, we also examined quota predictors as laid out by Krook (2010). These were the number of peacekeepers in a country from the 
International Peace Institute (IPI) Peacekeeping Database, net overseas development assistance (World Bank Indicator DT.ODA.ODAT.CD), and a series of measures of political competition and landscape from Beck et al. (2001). Our measure of democracy was gleaned from the Polity IV project database. This database records information on the political regime in 167 countries, between 1800 and 2014. The democracy indicator is available annually, and is a 0-10 scale based on measures of competitiveness of political participation, openness and competitiveness of executive recruitment, and constraints on executive powers. Higher values reflect more open, democratic societies.

Health expenditure at the country-year level was taken from the World Health Organization National Health Accounts (NHA) data series. These provide a measure of total health expenditure as a percentage of GDP, and are available for the years 1995-2013.

For the women's economic rights variable we exploit previously under-exploited cross-country rights data from the Cingranelli et al. (2013) dataset, which provides data on three different variables measuring political, economic, and social rights of women, for the period 1981-2011 for around 127 (in 1981) to 192 (in 2011) countries.

Maternal care inputs data. Recent data from the World Bank databank allow us to examine the state of maternal health care in a sub-set of countries and years. We use the two policy-relevant indicators measuring the percentage of pregnant women receiving prenatal care (indicator SH.STA.ANVC.ZS) and the percentage of all births attended by skilled health staff (indicator SH.STA.BRTC.ZS). These data are constructed and released by the World Bank using comparable measures from each country: specifically data from UNICEF, the State of the World's Children, ChildInfo, and the Demographic and Health Surveys. As such, these measures are only available in years and countries for which surveys were conducted, resulting in fewer observations than the yearly measures of maternal mortality. In our analysis we use the full set of data released in the World Bank databank.

Placebo outcomes. Data on male mortality for adults are available in the World Bank databank (indicator SP.DYN.AMRT.MA), based on measures from the United Nations Population Division, World Population Prospect and University of California, Berkeley, and Max Planck Institute for Demographic Research. This is measured as mortality between the ages of 15 and 60, per 1,000 male adults, and captures the likelihood that a male of age 15 dies by the age of 60 . Tuberculosis mortality is measured as the number of deaths due to tuberculosis among HIV-negative people, and is measured per 100,000 population. The data are from the WHO and were downloaded from: http://apps. who. int/gho/data/view. main. 57020ALL? lang=enonthe17/03/2016.

Women's suffrage and mortality rates in the United States. The state-specific adoption of women's suffrage is taken from Miller (2008), for 48 states and Washington, DC, Hawaii, and Alaska had not been granted statehood during the study period. State-year maternal mortality rates were obtained from Jayachandran et al. (2010), collated from US vital statistics data. These data are available for all states but Alaska, Hawaii, and Washington, DC. For 21 states these data are available for the entire period of 1920 to 1950. For the remaining states mortality data are incomplete, and available only from a later year onwards. ${ }^{23}$ In Table A10 we provide summary statistics for each relevant variable.

Women's representation in the Senate and US House of Representatives. We created a state by year database of the proportion of women in seats representing each state of the United States for the National Senate and the House of Representatives. A complete compilation of these data is available in Manning and Brudnick (2018). We calculated the proportion of women representatives in each chamber of congress for each state for the years 1917-60. Prior to 1917, there were no female representatives in either body.

\footnotetext{
${ }^{23}$ For four states from 1921 onwards, for three from 1922 onwards, for one from 1925, for two from 1926, for five from 1927, for three from 1928, for two from 1929, for one from 1932, and finally for one from 1933 onwards.
} 